\title{
Flower traits, habitat, and phylogeny as predictors of pollinator service: a plant community perspective
}

\author{
Carlos M. Herrera iD 1 \\ Estación Biológica de Doñana, Consejo Superior de Investigaciones Científicas, Avenida Americo Vespucio 26, E-41092 Sevilla, Spain
}

Citation: Herrera, C. M. 2020. Flower traits, habitat, and phylogeny as predictors of pollinator service: a plant community perspective. Ecological Monographs 90(2):e01402. 10.1002/ecm.1402

Abstract. Pollinator service is essential for successful sexual reproduction and long-term population persistence of animal-pollinated plants, and innumerable studies have shown that insufficient service by pollinators results in impaired sexual reproduction ("pollen limitation"). Studies directly addressing the predictors of variation in pollinator service across species or habitats remain comparatively scarce, which limits our understanding of the primary causes of natural variation in pollen limitation. This paper evaluates the importance of pollinationrelated features, evolutionary history, and environment as predictors of pollinator service in a large sample of plant species from undisturbed montane habitats in southeastern Spain. Quantitative data on pollinator visitation were obtained for 191 insect-pollinated species belonging to 142 genera in 43 families, and the predictive values of simple floral traits (perianth type, class of pollinator visitation unit, and visitation unit dry mass), phylogeny, and habitat type were assessed. A total of 24,866 pollinator censuses accounting for 5,414,856 flower-minutes of observation were conducted on 510 different dates. Flowering patch and single flower visitation probabilities by all pollinators combined were significantly predicted by the combined effects of perianth type (open vs. restricted), class of visitation unit (single flower vs. flower packet), mass of visitation unit, phylogenetic relationships, and habitat type. Pollinator composition at insect order level varied extensively among plant species, largely reflecting the contrasting visitation responses of Coleoptera, Diptera, Hymenoptera, and Lepidoptera to variation in floral traits. Pollinator composition had a strong phylogenetic component, and the distribution of phylogenetic autocorrelation hotspots of visitation rates across the plant phylogeny differed widely among insect orders. Habitat type was a key predictor of pollinator composition, as major insect orders exhibited decoupled variation across habitat types in visitation rates. Comprehensive pollinator sampling of a regional plant community has shown that pollinator visitation and composition can be parsimoniously predicted by a combination of simple floral features, habitat type, and evolutionary history. Ambitious community-level studies can help to formulate novel hypotheses and questions, shed fresh light on long-standing controversies in pollination research (e.g., "pollination syndromes"), and identify methodological cautions that should be considered in pollination community studies dealing with small, phylogenetically biased plant species samples.

Key words: floral traits; Mediterranean mountain habitats; phylogenetic niche conservatism; phylogenetic signal; plant community; pollinator composition; pollinator functional abundance; pollinator service.

\section{INTRODUCTION}

Most angiosperm plants are pollinated by animals, and pollinator service is essential to achieve successful sexual reproduction and long-term population persistence (Knight et al. 2005, Harder and Aizen 2010, Ollerton et al. 2011). Considerable research effort has been devoted over the years to elucidate the multiple implications of variation in pollinator service among individuals, species, habitats, or pollination modes. Within this conceptual framework, one traditional line of inquiry

Manuscript received 21 May 2019; revised 23 September 2019; accepted 11 November 2019. Corresponding Editor: Rebecca E. Irwin.

${ }^{1}$ E-mail: herrera@ebd.csic.es has analyzed the consequences of variation in pollinator service. This indirect approach to the study of pollinator service includes countless studies showing that insufficient quantity or quality of pollen delivery ("pollen limitation") often entails a reduction in the number or reproductive value of seeds (Gross and Werner 1983, Burd 1994, Harder and Aizen 2010, Bennett et al. 2018); empirical investigations on patterns of variation in pollen limitation among plant taxa, regions, communities or life forms (Johnson and Bond 1997, Larson and Barrett 2000, Vamosi et al. 2006, Alonso et al. 2012, 2013, Bennett et al. 2018); and theoretical treatments formulating evolutionary models (Ashman et al. 2004, Aizen and Harder 2007, Burd 2016, Harder et al. 2016). Thanks to this vast amount of work, the ecological and 
evolutionary consequences of variable pollinator service at different scales are now reasonably well understood. In contrast, studies directly addressing the causal factors explaining variation in pollinator service across species, habitats or regions remain comparatively scarce. This represents an important, albeit insufficiently recognized difficulty for achieving a better understanding of the constellation of factors affecting pollen limitation and reproductive success in animal-pollinated plants. As noted by Ashman et al. (2004: 2419) more than one decade ago, despite the wealth of data on pollen limitation "we [still] remain ill equipped to assess its causes" (see also Vamosi et al. 2013).

Pollinator service, which depends on a combination of pollinator visitation frequency and pollinator composition, is one of the most immediate causal factors contributing to variations in pollen limitation and reproductive success (Gómez et al. 2007, 2010). This is because the intensity of pollen deposition and removal often depends on the frequency of animal visits to flowers (Silander and Primack 1978, Rush et al. 1995, Engel and Irwin 2003; but see also, e.g., Hegland and Totland 2008), and different pollinator types vary in average pollinating efficacy or quality per visit (Herrera 1987, Sahli and Conner 2007, King et al. 2013). Following the lead of early pioneering work (Müller 1883, Knuth 1908, Robertson 1928), information on pollinator visitation frequency and composition has routinely formed part of nearly every published piece of pollination research, and vast amounts of qualitative and quantitative data have steadily accumulated in the literature over many decades. The rather puzzling scarcity of quantitative ecological studies aimed at recognizing predictors of natural variation in pollinator visitation and composition, and thus pollinator service, despite early claims pointing out its ecological significance (McCall and Primack 1992, Primack and Inouye 1993) and the availability of such an enormous literature database can be tentatively interpreted on four distinct grounds. First, with few exceptions (e.g., McCall and Primack 1992, Ollerton et al. 2009, Lázaro et al. 2013) the vast majority of investigations addressing pollinator visitation and/or composition of animal-pollinated plants at the plant community level have examined only small or modest numbers of plant species at a time (see, e.g., Ollerton 2017: Appendix 2 for review). Apart from the likely ecological or taxonomic biases to be expected in small species samples, the narrow range in flower traits, pollinator type, ecological conditions, or taxonomic/phylogenetic affiliation inherent to small samples reduces the statistical power for identifying predictors of pollinator visitation and composition. Second, among the scarce pollination studies dealing with a substantial number of species $(>100)$ very few have applied quantitative methods transcending simple binary scoring of plant-pollinator species associations (Interaction Web Database; available online). ${ }^{2}$ As

\footnotetext{
${ }^{2}$ https://www.nceas.ucsb.edu/interactionweb/resources.html
}

a consequence, attempts at elucidating broad-scale patterns of pollinator visitation and composition in large species samples have often relied on statistically suboptimal, binary plant-pollinator data (Herrera 1996, Waser et al. 1996, Olesen and Jordano 2002). Third, the enormous variety of observational methods and numerical measurements that have been applied so far in pollination studies poses insuperable difficulties for comparing data from different studies (Kearns and Inouye 1993), and also for turning results from different studies into aggregate datasets that could be used for broad quantitative analyses searching for predictors of pollinator visitation and composition. And fourth, irrespective of the methods used to record and numerically represent pollinator visitation and composition, pollination studies have infrequently estimated the uncertainty of whichever estimate of pollinator service was used (but see, e.g., Motten 1986, Inouye and Pyke 1988, McCall and Primack 1992, Gómez et al. 2007, Herrera 2019). This hinders the application of formal statistical tests for addressing explicit hypotheses on predictors of pollinator service, including possible meta-analyses.

This paper presents the results of an investigation designed to assess the importance of pollination-related plant features, evolutionary history, and environmental conditions as predictors of pollinator service in a large sample of plant species from undisturbed montane habitats in southeastern Spain. Quantitative data on pollinator visitation and composition were obtained for a substantial fraction of the regional plant community of insect-pollinated plants, and then related to several floral traits, phylogeny, and type of habitat to evaluate their predictive value. The strength and novelty of this study rest on the combination of an unusually large species sample; considerable pollinator sampling effort; field sampling methods yielding extensively replicated quantitative data on pollinator visitation and composition amenable to powerful statistical analyses; and the application of recent implementations of generalized linear mixed models for the study of pollinator functional abundance (Herrera 2019). The consistent use of mixed linear models where plant species, sampling sites and sampling years were all treated as random effects, will allow drawing of conclusions referred to a broad inference space and answering broad ecological questions whose scope transcends the limits of the specific samples studied (McLean et al. 1991, Bolker 2015, Herrera 2019).

\section{Materials ANd Methods}

\section{Study area}

Data on pollinator visitation analyzed in this paper were collected during February-December 1997-2018 (with a gap in 2000-2002) in a relatively small area of the Sierras de Cazorla-Segura-Las Villas Natural Park, Jaén Province, southeastern Spain. This region is 
characterized by extensive areas of well-preserved mountain habitats and outstanding biological diversity (Médail and Diadema 2009, Gómez Mercado 2011, Molina-Venegas et al. 2015). Sampling sites $(N=42$; Appendix S1, distance between sites $\leq 21 \mathrm{~km}$ ) were spread over all altitudinal belts of vegetation occurring in the region (elevation range 770-1,920 $\mathrm{m}$ above sea level). Study sites were a superset of the $N=29$ locations studied by Herrera (2019). Major vegetation types from lower to higher elevations included Quercus rotundifoliadominated, Mediterranean evergreen forest and tall scrubland; mixed Pinus nigra or $P$. pinaster forest with Quercus and Acer; and various types of mature Pinus nigra forests and woodlands differing in age, height, and tree density.

\section{Plant species sample}

Pollinator visitation to flowers was assessed for 191 plant species belonging to 142 genera in 43 families (Table 1). This sample is a superset of the 65 species in 28 families studied by Herrera (2019), and includes species from $73 \%$ of families, and $\sim 85 \%$ of widely distributed or common species, of entomophilous plants in the Sierra de Cazorla region (Gómez Mercado 2011; C. M. Herrera, unpublished data). Mean pollinator sampling date for each species roughly matched its peak flowering date. The seasonal distribution of sampling times in the species sample (Table 1) closely matched the seasonal pattern of flowering times in the region, with most species flowering in June and July. Asteraceae (39 species), Lamiaceae (24 species), Brassicaceae (10), Fabaceae (10), Rosaceae (9), and Cistaceae (8) contributed about one-half of species to the sample. Hemicryptophytes (72 species), chamaephytes (41), geophytes (33), and therophytes (27) were the predominant life forms (Table 1).

\section{Sampling scheme}

The goal of this study was to collect quantitative data on pollinator visitation for as many different plant species as possible so that most regional phylogenetic, ecological, and floral diversity was eventually sampled. Considerable attention was paid to avoiding conscious or unconscious biases favoring species from particular habitat types, blooming at convenient times of year, yielding high data/sampling effort ratios, or having particular pollinator types (e.g., easily identifiable or largesized ones). Obtaining robust quantitative pollinator data for a large, ecologically and phylogenetically unbiased species sample required spanning fieldwork over many years, since pre-established replication rules (see Pollinator visitation) limited the number of species that could be sampled per flowering season. About twothirds of species in the sample $(N=126)$ were sampled for pollinators in only one year and the rest were sampled for two or more years as part of the research on long-term changes in pollinator abundance in relation to climate change reported by Herrera (2019). Pollinator sampling was conducted on a single site in the vast majority of the species considered here $(N=181)$, while 10 species that were part of other investigations were sampled on two or more sites (e.g., Aquilegia cazorlensis, Aquilegia vulgaris, Helleborus foetidus, Lavandula latifolia, Narcissus longispathus; Table 1). The distribution of pollinator sampling effort among plant species, years and sites is shown in Table 1. Species-year combinations were chosen randomly, subject only to constraints set by time availability, finding suitable populations, and sampling site accessibility, the choice being thus uninformed by, e.g., phenology or flowering intensity (see also Herrera 2019).

\section{Pollinator visitation}

Quantitative data on pollinator visitation were obtained by applying the same standardized sampling protocol for all plant species studied (Herrera 2019). The basic sampling unit was the "pollinator census," consisting of a 3-minute watch of a flowering patch whose total number of open flowers was also counted. All pollinators visiting some flower in the focal patch during the 3-minute period were identified (see Pollinator identification), and total number of flowers probed by each individual was recorded. Areal extent and number of open flowers in monitored patches were adjusted for each plant species according to flower size and density, so that all pollinator activity in the patches could be confidently monitored from a distance of 1.5-2.0 m. Mean number of flowers in censused patches for each species is shown in Appendix S2: Table S1. Some species had tiny flowers densely packed into compact inflorescences (e.g., Apiaceae, Asteraceae, Dipsacaceae; $N=53$ species, Table 1), which rendered impractical assessing the number of elemental florets visited by pollinators. In these cases, the number of inflorescences available per patch and visited per census was counted rather than individual flowers, and visitation probabilities (see Data analysis) thus actually refer to inflorescences. For simplicity, I will refer to visitation to both single flowers and inflorescences as "flower visitation." In some analyses, however, the two types of visitation units will be considered as levels of the discrete variable "visitation unit," one of the predictors of pollinator visitation considered here ("single flowers" vs. "flower packets"; Appendix S2: Fig. S1; see Data analysis).

Census replication rules for each species-site-year combination were as in Herrera (2019). A minimum of 60 censuses spread over three non-consecutive dates should be conducted on $\geq 20$ widely spaced flowering patches with roughly similar flower numbers. On each date, censuses should be distributed from 0.5 to $2.5 \mathrm{~h}$ past sunrise (depending on season; censuses started earlier in summer) through one hour past noon, the different patches being watched in random order. Flowers of 


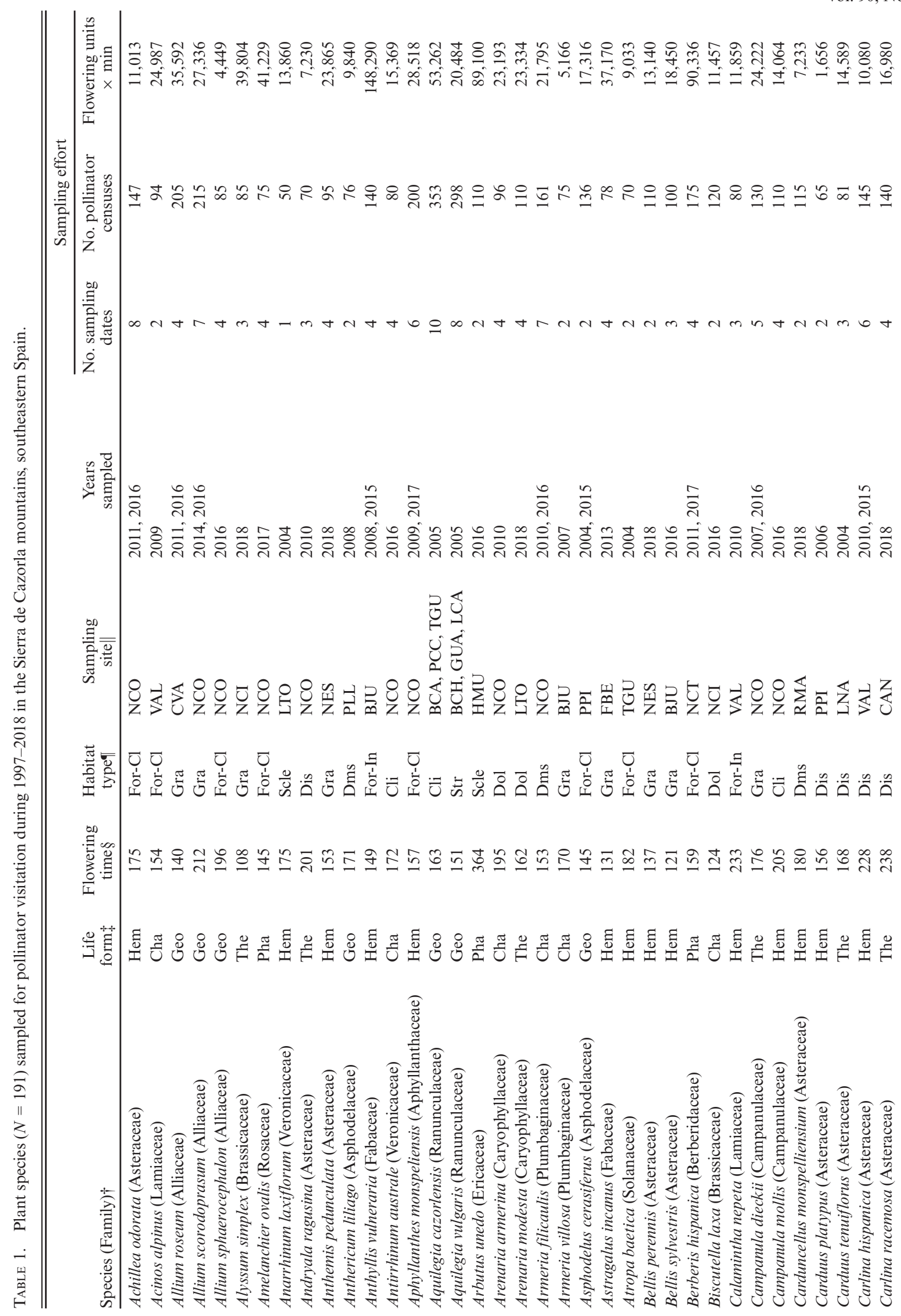




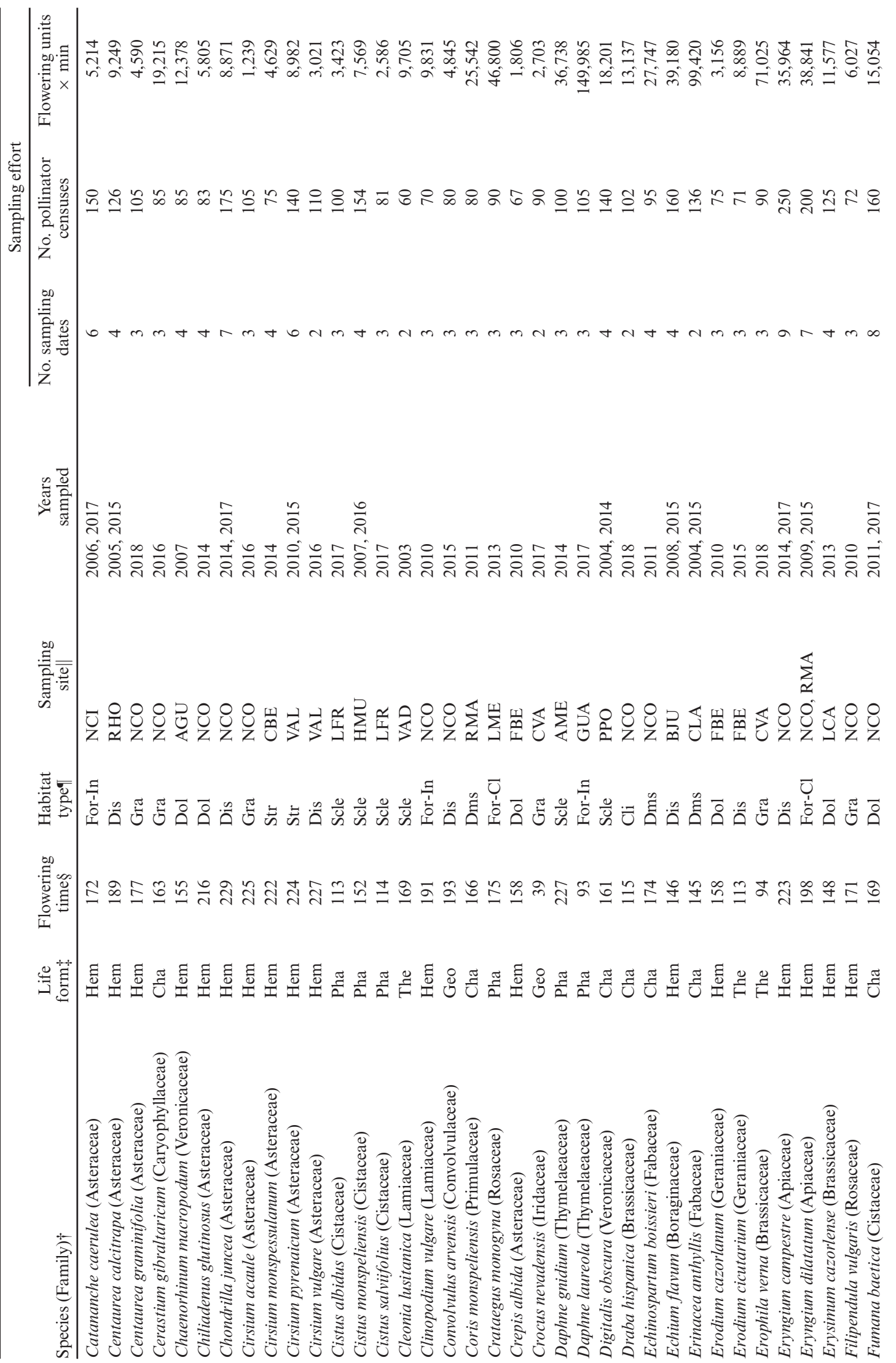




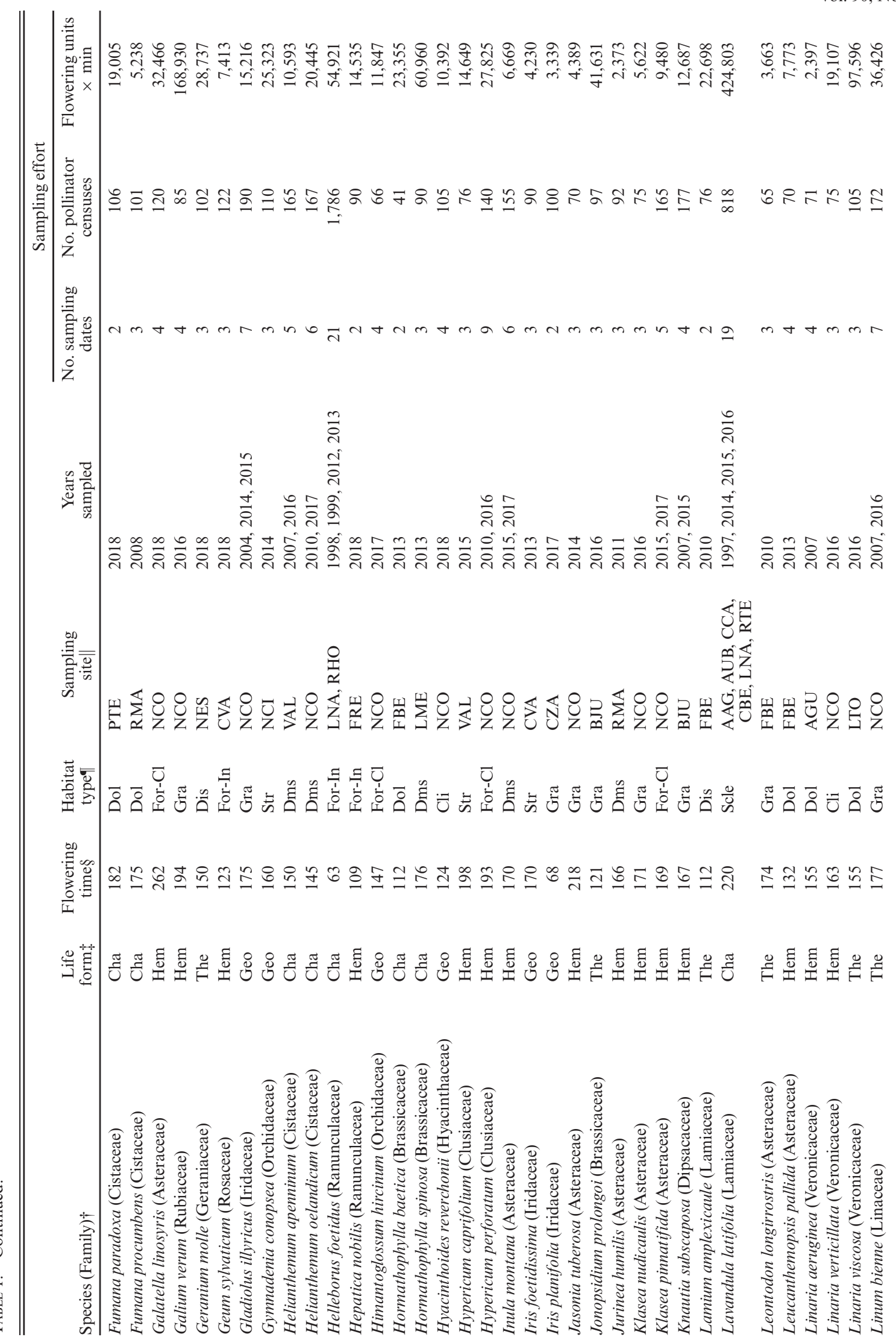




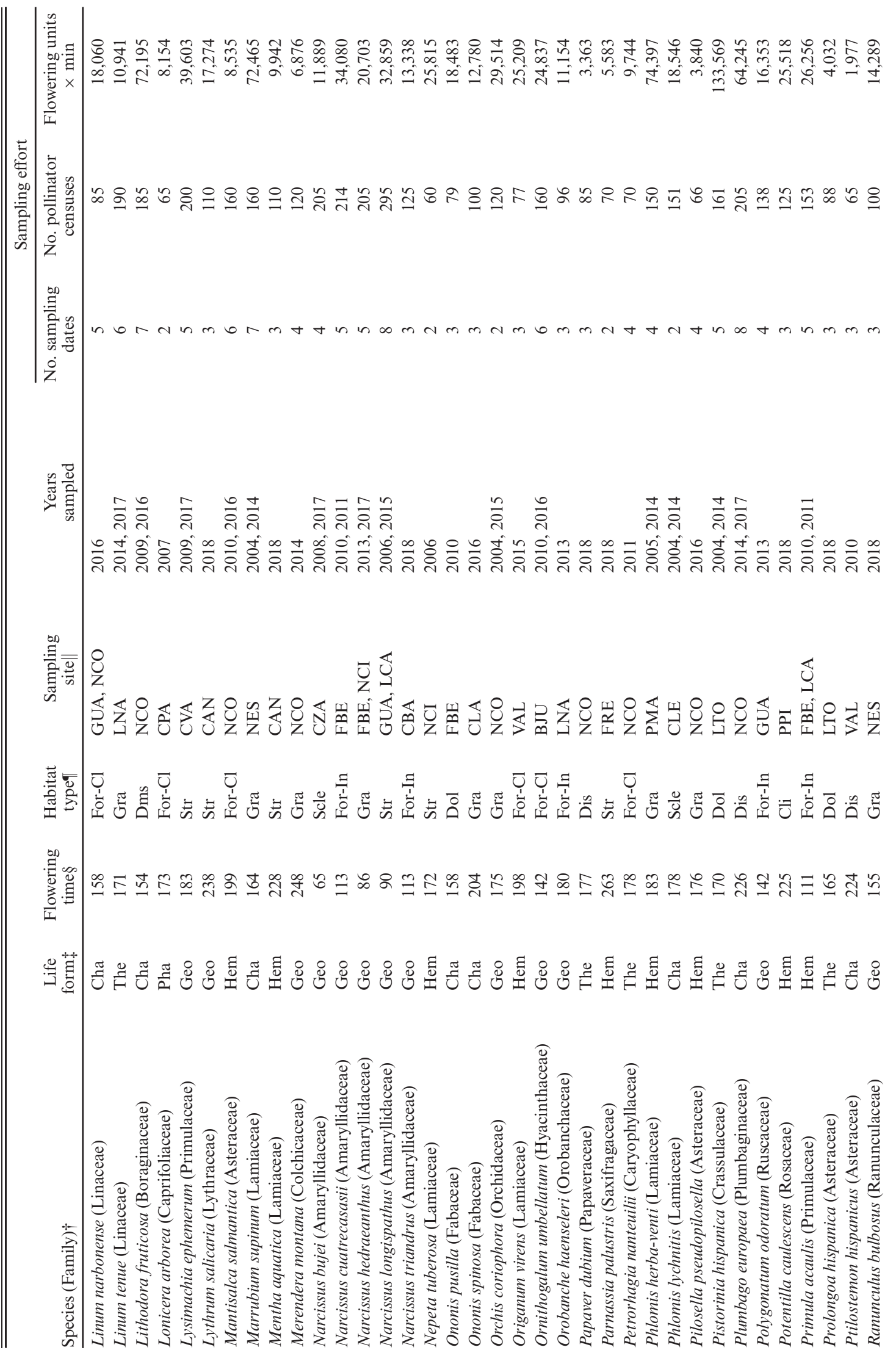




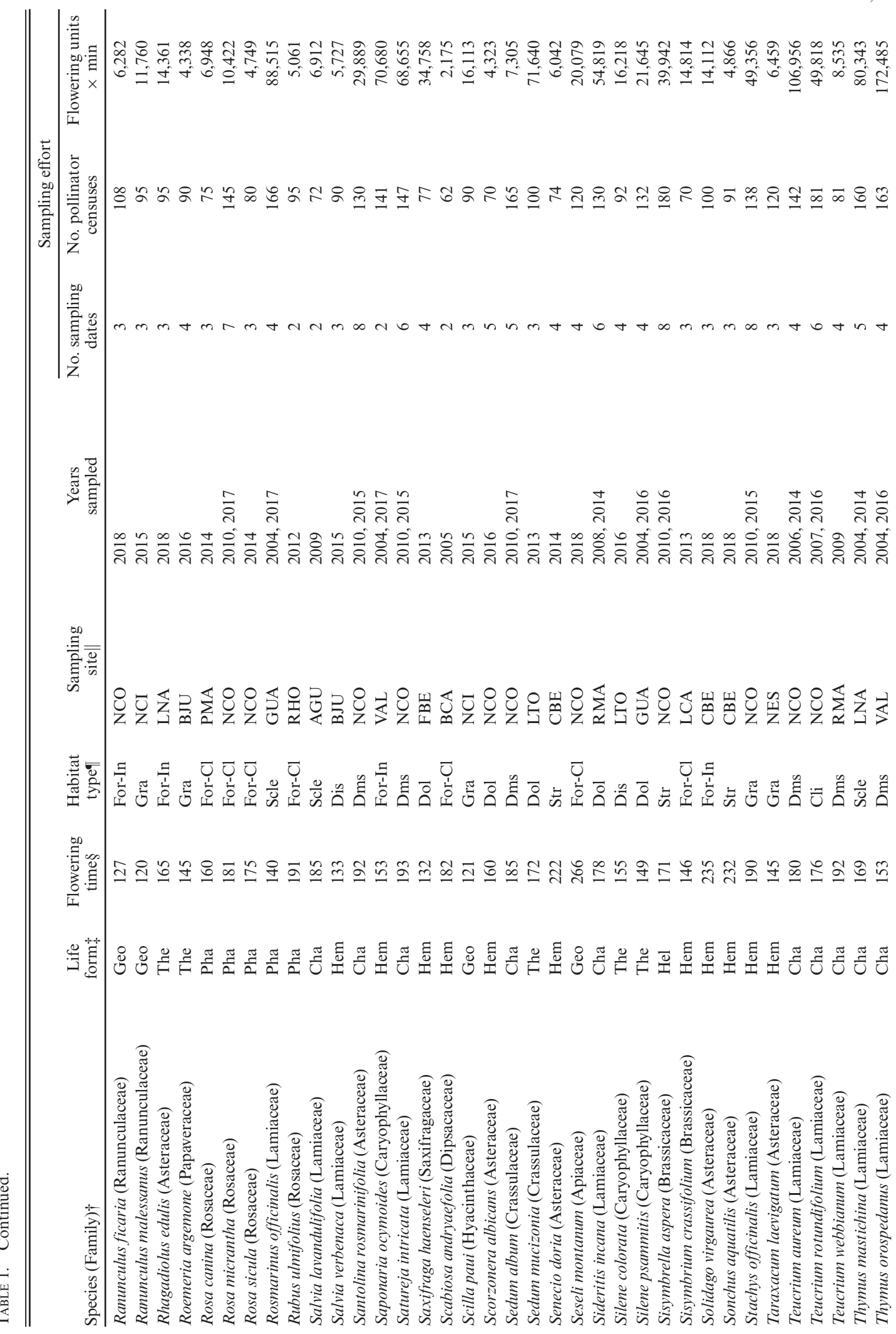




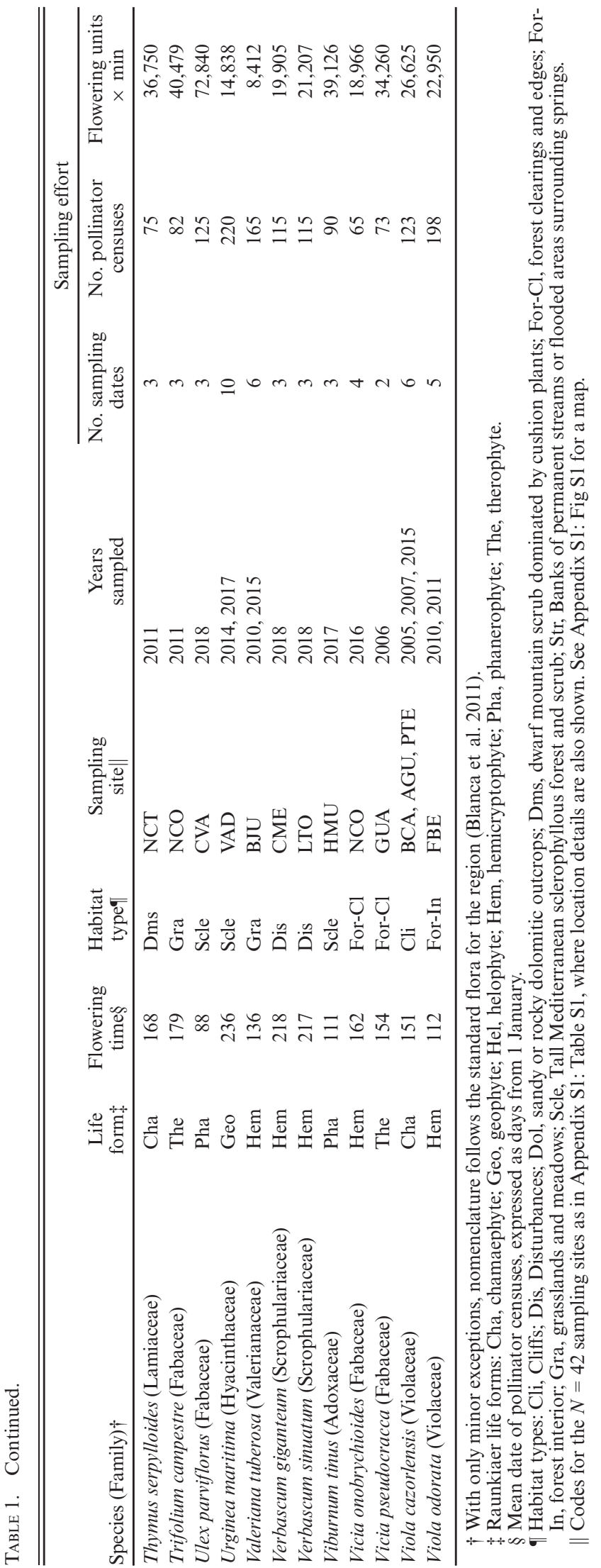


about one-third of species studied are not available to pollinators in the afternoon, as their corollas wither, close, or fall shortly after noon, and earlier studies in the area have also shown that insect pollinator activity declines considerably in the afternoon (Herrera 1990, 1995a; C. M. Herrera, personal observations). For four species (Daphne gnidium, D. laureola, Origanum virens, Silene colorata) there was some circumstantial evidence suggesting the existence of additional crepuscular or nocturnal pollinators (e.g., crab spiders with captured moths). Several factors precluded fulfilling all the preceding rules for some species in some sites or years, including long spells of poor weather, logistic problems and destruction of flowering patches by herbivorous mammals. Number of distinct sampling dates, number of censuses, and flower-minutes of observational effort for every species are summarized in Table 1. This study is based on pollinator visitation data obtained in a total of 24,866 pollinator censuses carried out on 510 different dates and accounting for a total watching effort of 5,414,856 flower-minutes. With the only exceptions noted in Acknowledgments (Helleborus foetidus, Aquilegia vulgaris), I conducted all censuses throughout this study personally, thus results are unaffected by inter-observer heterogeneity.

\section{Pollinator identification}

Pollinators recorded during censuses were identified using the methods described by Herrera (2019). Insect taxonomists that contributed identifications for this study are listed in Acknowledgments. Out of a total of 30,463 individual pollinators recorded in censuses, $79.1 \%$ were identified to species, $4.1 \%$ were assigned to cryptic species pairs of congeneric species, and $15.6 \%$ were identified to genus. Orders will be the only taxonomic level considered in this paper. Close-up photographs of pollinators visiting flowers were taken routinely during censuses using a DSLR digital camera and $105 \mathrm{~mm}$ macro lens. These photographs were used for insect identification, keeping photographic vouchers of pollinators, and ascertaining the pollinating status of different insect taxa. Only taxa whose individuals contacted anthers or stigmas, or had visible pollen grains on body surfaces, are considered as pollinators in this study.

\section{Data analysis}

Pollinator visitation. - Two probabilistic measurements will be used here as complementary descriptors of pollinator service, namely "patch visitation probability" and "flower visitation probability," which depict the probability of a flowering patch or a single flower being visited by some pollinator during a 3 -minute census. These two measurements estimate pollinator service from the viewpoint of the local flowering plant population and single flowers, respectively. Each pollinator census provided point estimates of patch visitation (probability of at least one flower in a patch being probed during a 3-minute period) and flower visitation (probability of an individual flower being probed during a 3-minute period) probabilities, and replication of censuses allowed calculation of parameter estimates in models and associated uncertainty measurements. See Herrera (2019) for additional details and discussion on the motivation and advantages of framing pollinator functional abundance in these probabilistic terms.

The broad-scale pattern of interspecific variation in proportional pollinator composition in the sample of species studied was explored by performing nonmetric multidimensional scaling (NMDS) on the matrix of pairwise interspecific dissimilarity (Bray-Curtis distance) in proportional importance of the four major insect orders. NMDS provided an objective assessment of major trends in pollinator composition occurring in the sample. Computations were performed with the function metaMDS in the package vegan (Oksanen et al. 2019) for the R computing environment ( $\mathrm{R}$ Core Team 2018; all statistical analyses in this paper were carried out using R). To assess the relative importance of interspecific variation in the species sample in relation to variation between sites and years, total sample variance in patch and flower visitation probabilities was dissected into components due to variance among plant species, sampling sites, and sampling years. Generalized linear mixed models were fitted to pollinator census data, where plant species, sampling site and sampling year were included as random effects, an intercept as the only fixed effect, and patch and flower visitation probabilities were the response variables, modeled as binomial processes. For each response variable, independent analyses were conducted for all pollinator taxa combined and for each major insect order separately.

Floral and ecological predictors-Three species-specific floral features were examined as potential predictors of pollinator visitation: class of floral perianth, type of pollinator visitation unit (single flower vs. flower packet; Appendix S2: Fig. S1), and mean dry mass of visitation unit ( $\log _{10}$-transformed for the analyses). All plant species were characterized for each of these three variables (Appendix S2: Table S1). Two discrete perianth classes were recognized, corresponding respectively to open, more or less bowl-shaped, non-restrictive perianths ("open perianth" hereafter, $N=123$ species), and closed, tubular, sympetalous or otherwise restrictive perianths ("restrictive perianth" hereafter, $N=68$ species). Mean dry mass of the visitation unit was obtained for each species by weighing samples of flowers or flower packets collected at census localities. Samples were dried in an oven until constant mass prior to weighing. Dry mass of the visitation unit was used here as a convenient surrogate for overall size, which could influence pollinator visitation through effects on pollen or nectar production. The broad heterogeneity in morphology and structure of visitation units occurring in the sample precluded 
dissection of flowering unit mass into components with different functionalities in relation to pollinators that were comparable across species. This should be inconsequential in the context of overall analyses because of the expected positive relationship between overall flower size and pollinator reward or attraction (e.g., Plowright 1981, Herrera 1985, Stanton and Preston 1988).

To assess possible environmental influences on pollinator service, each plant species was assigned to one of the following nine habitat types (total species per habitat in parentheses): vertical rock cliffs (nine species); local disturbances caused by humans, large mammals, or natural abiotic processes (21); sandy or rocky dolomitic outcrops (23); dwarf mountain scrub dominated by cushion plants (21); forest edges and large clearings (30); forest interior (18); patches of grasslands and meadows on deep soils in relatively flat terrain (35); tall, dense Mediterranean sclerophyllous forest and scrub (17); banks of permanent streams or flooded/damp areas around springs (17). Individual species' assignments to habitat types are shown in Table 1 . In the case of species that occurred in more than one of these habitat types ( $\sim 15 \%$ of total), the assignment considered only the habitat where pollinator censuses were conducted, for it was impractical to sample these species in all habitats where they occurred. This should be inconsequential to results, since plant species and sampling sites were treated as random effects in the analyses (see next paragraph) and conclusions on variation among habitats referred to a broad inference space beyond the limits of the specific samples studied.

Two sets of generalized linear mixed models were fitted to the data to test the effects on patch and flower visitation probability of species-specific floral traits (perianth type, visitation unit type, visitation unit mass) and habitat type, respectively, which were in each case included as fixed effects. In each set of analyses, independent models were fitted using as response variables the visitation probability by all pollinators combined and by each major insect order considered separately. Binomial error distribution and logit link function were used in all models, and plant species, sampling site, and sampling year were included as random effects. For a large subset of species considered here, Herrera (2019) found that in the vast majority of species the number of flowers per patch was directly related to patch visitation probability, and inversely related to flower visitation probability. Furthermore, in the study area patch and flower visitation probabilities increased from winter through spring to summer (C. M. Herrera, unpublished data). To account statistically for these effects, the number of flowers in each censused patch (scaled and centered) and the date of the census (expressed as days from 1 January, scaled and centered) were included in all models as fixed-effect covariates.

All generalized linear mixed models in this paper were fitted with the glmer function in the lme4 package (Bates et al. 2015). They were checked for overdispersion using function dispersion_glmer from the blmeco library (Korner-Nievergelt et al. 2015). Weak overdispersion of some models was fixed by adding observation-level random effects to the data (Bolker 2015). Statistical significance of fixed effects was determined by analysis of deviancebased, Type II Wald chi-square tests using the ANOVA function from the car package (Fox and Weisberg 2011). Confidence intervals of fixed effect parameter estimates were obtained using the profile likelihood method implemented in the confint.merMod function of the lme4 package. The function ggpredict from the ggeffects package (Lüdecke 2018) was used to compute marginal effects of single predictors on measurements of pollinator visitation holding constant the rest of fixed effects in the model.

Phylogenetic effects. - The relationship between pollinator visitation and plant phylogeny was examined by constructing a phylogenetic tree for the set of species studied and testing for the presence of a phylogenetic signal in the species means for patch and flower visitation probability, for all pollinators combined and separately for each major insect order. The phylogenetic tree was obtained using the phylomatic function in the brranching package and the default storedtree = "R20120829" (Chamberlain 2018). Tree branch lengths were set to unity and polytomies resolved randomly using utility functions compute.brlen and multi2di in the ape package, respectively (Paradis and Schliep 2018). Phylogenetic signal in pollinator visitation, defined as "a tendency for related species to resemble each other more than they resemble species drawn at random from the tree" (Blomberg and Garland 2002) was assessed with Pagel's $\lambda$. This statistic, which assumes a Brownian motion model of quantitative trait evolution, seems strongly robust to incompletely resolved phylogenies or suboptimal branch-length information, and can be used to assess the strength, or "effect size," of phylogenetic structuring (Münkemüller et al. 2012, Molina-Venegas and Rodríguez 2017). To identify relevant "local hotspots" of phylogenetic autocorrelation contributing disproportionately to overall phylogenetic signal in pollinator visitation, local Moran's $I\left(I_{\mathrm{i}}\right)$ was computed for each tip of the phylogenetic tree. This local indicator of phylogenetic association (LIPA; Keck et al. 2016) allows for the decomposition of global phylogenetic signal into the contributions due to individual observations, and the LIPA for each tip in the phylogeny gives an indication of the extent of significant phylogenetic clustering of similar values around that tip (Anselin 1995). Computations were performed using the package phylosignal (Keck et al. 2016), and statistical significance of Pagel's $\lambda$ and $I_{\mathrm{i}}$ was tested by randomization.

A regression approach (Grafen 1989) based on phylogenetic generalized least squares (PGLS; Paradis 2012, Symonds and Blomberg 2014) was adopted to evaluate the importance of habitat type as predictor of patch and flower visitation probabilities after statistically 
accounting for the phylogenetic correlations underlying pollinator visitation data. Generalized linear mixed models were fitted to species mean values using restricted maximum likelihood estimation, with either mean patch or mean flower visitation probabilities as response variables. For each response variable, separate analyses were performed for all pollinators combined and for each major insect order separately. Phylogenetic correlations were incorporated into the models by setting the variance-covariance structure between species to match that expected under a Brownian motion process of evolution on the phylogenetic tree (Paradis 2012, Symonds and Blomberg 2014). Computations were performed with function gls in the nlme package (Pinheiro et al. 2018). The covariance structure between species was obtained from the phylogenetic tree using the corBrownian function of the ape package (Paradis 2012, Paradis and Schliep 2018).

\section{RESULTS}

\section{The pollinators}

Regional assemblage.-Hymenoptera (47.5\% of individuals), Diptera $(19.9 \%)$, Coleoptera $(16.8 \%)$, and Lepidoptera $(15.2 \%)$ accounted for nearly all pollinators recorded ( $N=30,463$ individuals) in the $N=191$ plant species studied. Three additional insect orders, Hemiptera, Neuroptera, and Orthoptera, contributed altogether $0.5 \%$ of all individuals and will not be considered hereafter. Coleoptera, Diptera, Hymenoptera, and Lepidoptera were recorded in $62.3 \%, 88.5 \%, 97.9 \%$, and $62.3 \%$ of plant species studied, respectively.

Pollinators identified at least to genus $(N=30,121)$ belonged to 314 insect genera. Diptera (106 genera) exhibited the highest generic diversity, followed in decreasing order by Hymenoptera (86), Lepidoptera (62), and Coleoptera (53). Bees (families Andrenidae, Apidae, Colletidae, Halictidae, Megachilidae) accounted for nearly all the Hymenoptera recorded $(95.5 \%$ of individuals). Truncated genus abundance curves for the 20 most abundant genera in each order are shown in Appendix S3: Fig. S1. Dominance was similarly high in all orders, with a few genera accounting for most individuals in every case: Anthrenus, Lobonyx, and Dasytes were the three most abundant genera of Coleoptera (36.9\% of total); Sphaerophoria, Bombylius, and Eristalis of Diptera (32.9\%); Argynnis, Thymelicus, and Melanargia of Lepidoptera (41.0\%); and Bombus, Andrena, and Lasioglossum of Hymenoptera (33.5\%).

Individual plant species' assemblages. - Nearly all species studied had taxonomically diverse pollinator assemblages at the insect order level (Appendix S3: Table S1). Only 14 species ( $7.3 \%$ of total) had pollinators belonging to single insect orders (e.g., Diptera: Saponaria ocymoides; Hymenoptera: Digitalis obscura, Iris foetidissima, Ononis spinosa; Lepidoptera: Gymnadenia conopsea), while as many as 152 species ( $79.6 \%$ of total) had pollinators from three or four different insect orders (Appendix S3: Table S1). With few exceptions, the proportional contributions of Coleoptera and Lepidoptera were consistently low in most plant species, while the relative importance of Diptera and, particularly, Hymenoptera varied extensively (Appendix S3: Fig. S2). Ordination analysis of the matrix of interspecific dissimilarity in proportional importance of the four major insect orders revealed an essentially continuous, bivariate distribution of species over the reduced two-dimensional space obtained (Fig. 1). The cloud of points was roughly centered on the bivariate origin $(0,0)$, which corresponded to comparable contributions of the four insect orders, and there was no evidence of clusters or gaps indicative of the presence in the sample of distinct groups of species with contrasting, differentiated pollinator types (Fig. 1). Some species falling around or beyond the periphery of the rather compact 191-species cluster did have pollinator assemblages strongly dominated by single insect orders. These included, for instance, Gymnadenia conopsea, Carduus platypus (Lepidoptera), Saponaria ocymoides, Arenaria modesta (Diptera), Cistus monspeliensis, Daphne laureola (Coleoptera), Digitalis obscura, and Helleborus foetidus (Hymenoptera; Fig. 1; see Appendix S3: Table S1 for details).

\section{Sample variance components of pollinator visitation}

For all pollinator taxa combined, variation among plant species in pollinator visitation probabilities was by far the chief source of sample variance in the whole data set, and results were comparable for patch and flower visitation probabilities (Table 2). Closely similar results were obtained when variance components due to species, sites, and years were computed only for subsets of species that were sampled on more than one year $(N=65$ species, Appendix S4: Table S1) or more than one site ( $N=10$ species, Appendix S4: Table S2). For the whole species sample, similar patterns held when separate analyses were conducted for each major insect order, although there existed some differences among orders in the variance structure of patch and flower visitation probabilities. Sample variance due to interspecific variation was highest for visitation by Coleoptera and Lepidoptera, and lowest for Diptera and Hymenoptera (Fig. 2), thus denoting greater interspecific heterogeneity in patch and flower visitation probabilities by the former two pollinator groups.

The important interspecific variation in pollinator visitation occurring in the sample was also apparent in the broad range of species means for patch and flower visitation probabilities (Fig. 3), which spanned nearly three orders of magnitude. Mean patch visitation probability per 3-minute period ranged between 0.0049 (Viola cazorlensis) and 0.9857 (Jasonia tuberosa), or a 200-fold variation. Mean flower visitation probability ranged between 0.0033 (Linaria verticillata) and 0.644 (Scabiosa andryaefolia), or a 195-fold variation. Reciprocals of these 


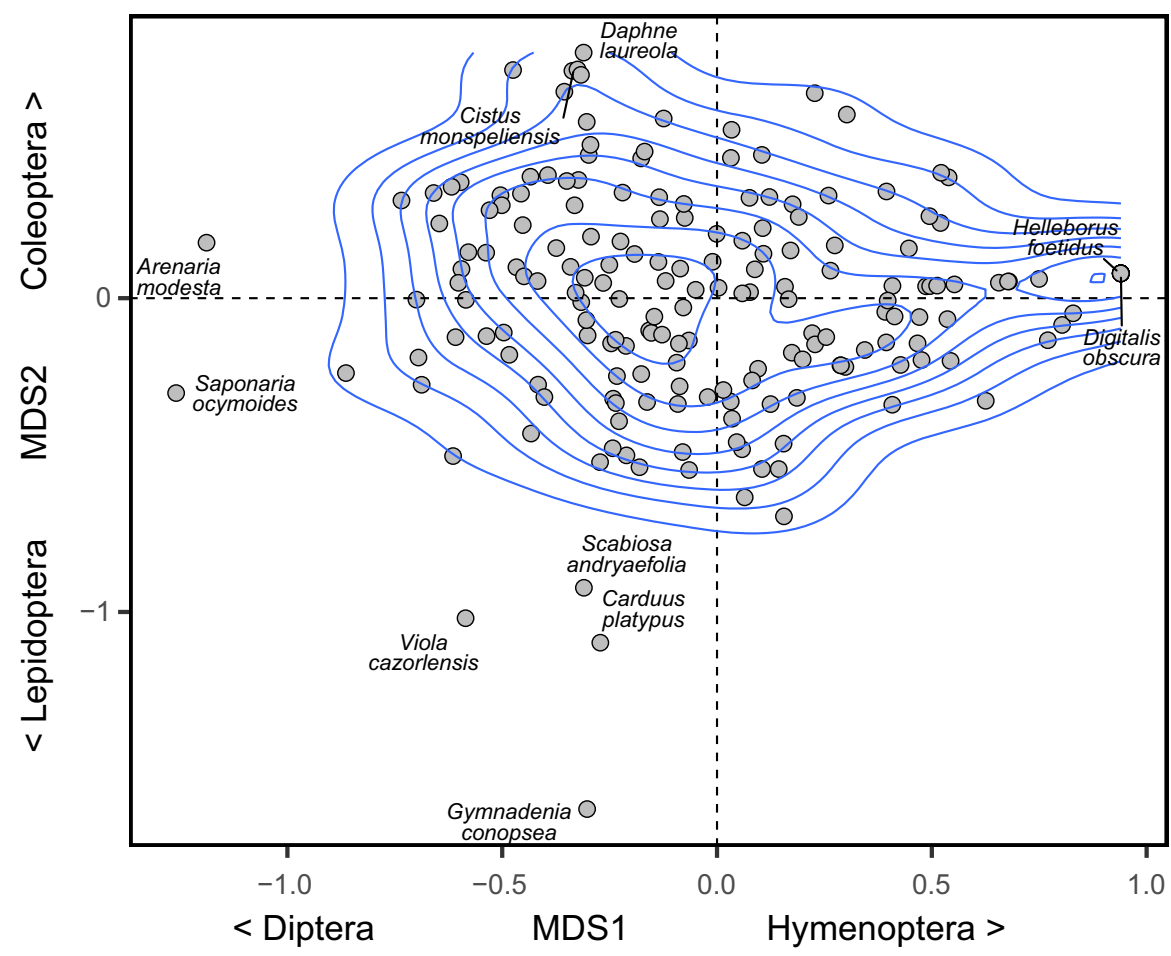

FIG. 1. Distribution of the $N=191$ plant species studied over the plane defined by the two axes (MDS1, MDS2) obtained by applying nonmetric multidimensional scaling to the matrix of pairwise interspecific dissimilarities in proportional pollinator composition (percent individuals contributed by each major insect order; data shown in Appendix S3: Table S1). Annotations along the two ordination axes are intended to provide rough indications of the main trends of variation underlying the two axes. Blue contour lines show the results of a two-dimensional kernel density estimation, depicted to emphasize the essentially continuous, bivariate distribution of species over the MDS1-MDS2 plane. A selection of "outlier" plant species characterized by exclusive or nearly exclusive dominance of Coleoptera (top), Diptera (left), Lepidoptera (bottom) or Hymenoptera (right) in their pollinator assemblages are individually identified in the graph.

figures indicate that the estimated time between consecutive insect visits to individual flowers, or "waiting time" between consecutive visits, ranged between 4.7 minutes (S. andryaefolia) and $15.2 \mathrm{~h}$ (L. verticillata). The shapes of frequency distributions of species means differed markedly for patch and flower visitation probabilities. While species means for patch visitation probability were roughly symmetrically distributed around the median, the distribution of species means for flower visitation probability was strongly skewed to the right, with most species falling around the lowermost extreme of the flower visitation probability range (Fig. 3).

\section{Pollinators and floral features}

All pollinators combined-Generalized linear mixed models fitted to pollinator census data that included pollinator census date (days from 1 January) and number of flowers per patch as fixed-effect covariates, revealed that patch and flower visitation probabilities by all pollinators combined were significantly related to perianth type (open vs. restrictive), visitation unit type (single flower vs. flower packet), and mass of visitation unit $\left(\log _{10^{-}}\right.$ transformed; Appendix S5: Table S1). In general, patch and flower visitation probabilities tended to be higher for flowers with open perianths or arranged in flower packets, and visitation probabilities increased with increasing mass of visitation unit (Fig. 4). Nevertheless, simple interpretations of the effects of floral traits on pollinator visitation were precluded by the statistically significance of two- and three-way interactions between predictors (Appendix S5: Table S1).

Interactions of floral traits on predicted marginal effects on patch and flower visitation probabilities, all pollinators combined, are illustrated in Fig. 4. Single flowers with open perianths had predictably higher visitation probabilities than single flowers with restrictive perianths over most of the range of visitation unit mass. This relationship did not hold when visitation units consisted of flower packets, for which visitation probabilities were higher for flowers with restrictive perianths for much of the range of visitation unit mass. In flowers with open perianths, but not in those with restrictive perianths, patch and flower visitation probabilities increased steadily with increasing mass of visitation unit. In flowers with restrictive perianths, predicted patch and flower visitation probabilities declined with increasing mass of visitation unit when visitation units were single flowers, 
TABLE 2. Variance components of patch and flower visitation probability (all pollinators combined) accounted for by plant species, sampling site, and sampling year in the data set studied.

\begin{tabular}{lcc}
\hline \hline & \multicolumn{2}{c}{ Variance $(95 \%$ confidence interval) } \\
\cline { 2 - 3 } Random effect & $\begin{array}{c}\text { Patch visitation } \\
\text { probability }\end{array}$ & $\begin{array}{c}\text { Flower visitation } \\
\text { probability }\end{array}$ \\
\hline $\begin{array}{c}\text { Plant species } \\
(N=191)\end{array}$ & $1.429(1.143-1.805)$ & $1.610(1.304-2.015)$ \\
$\begin{array}{c}\text { Sampling site } \\
(N=42)\end{array}$ & $0.147(0.059-0.363)$ & $0.491(0.270-0.939)$ \\
$\begin{array}{c}\text { Sampling year } \\
(N=19)\end{array}$ & $0.068(0.026-0.178)$ & $0.235(0.122-0.519)$ \\
\hline
\end{tabular}

Notes: Variance components were obtained by fitting generalized linear mixed models to the pollinator census data ( $N=24,866$ pollinator censuses), with species, site, and year as random effects and the intercept as the only fixed effect. Response variables were modeled as binomial processes. Patch visitation probability is the probability of at least one flower in a patch being probed during a 3-minute period. Flower visitation probability is the probability of visitation of an individual flower during a 3-minute period.

but the trend was reversed when visitation units consisted of flower packets.

Major insect orders. - Patch and flower visitation probabilities by each major insect order were significantly related to perianth type, visitation unit type, and mass of visitation unit, and in every case, there were also statistically significant interactions among floral traits (Appendix S5: Table S1). Major insect groups differed widely in detailed aspects of the relationships between visitation probabilities and combinations of floral features, as shown by the interaction graphs shown in Fig. 4. Among plants with single flowers and open perianths, visitation by Coleoptera and Hymenoptera, but not by Diptera and Lepidoptera, increased steeply with increasing visitation unit mass. In species with single flowers and restrictive perianths, in contrast, there was a steep decline in visitation by Diptera and Lepidoptera, but not by Coleoptera and Hymenoptera, with increasing visitation unit mass. In plants with flower packets as visitation units, patch and flower visitation probabilities by Hymenoptera and, particularly, Lepidoptera, increased with increasing visitation unit mass, while visitation by other groups remained stable (Diptera) or declined slightly (Coleoptera), and patterns were closely similar for species with open and restrictive perianths. Taken together, these results denote sharply contrasting, complex responses of the four major insect groups to interspecific variation in individual floral features and, particularly, the different trait combinations represented in the large set of plant species studied.

\section{Pollinators and phylogenetic relationships}

The phylogenetic tree depicting evolutionary relationships among the plant species studied is shown in Appendix S6: Fig. S1. The hypothesis that mean values of patch and flower pollinator visitation probabilities for individual plant species were independent from their

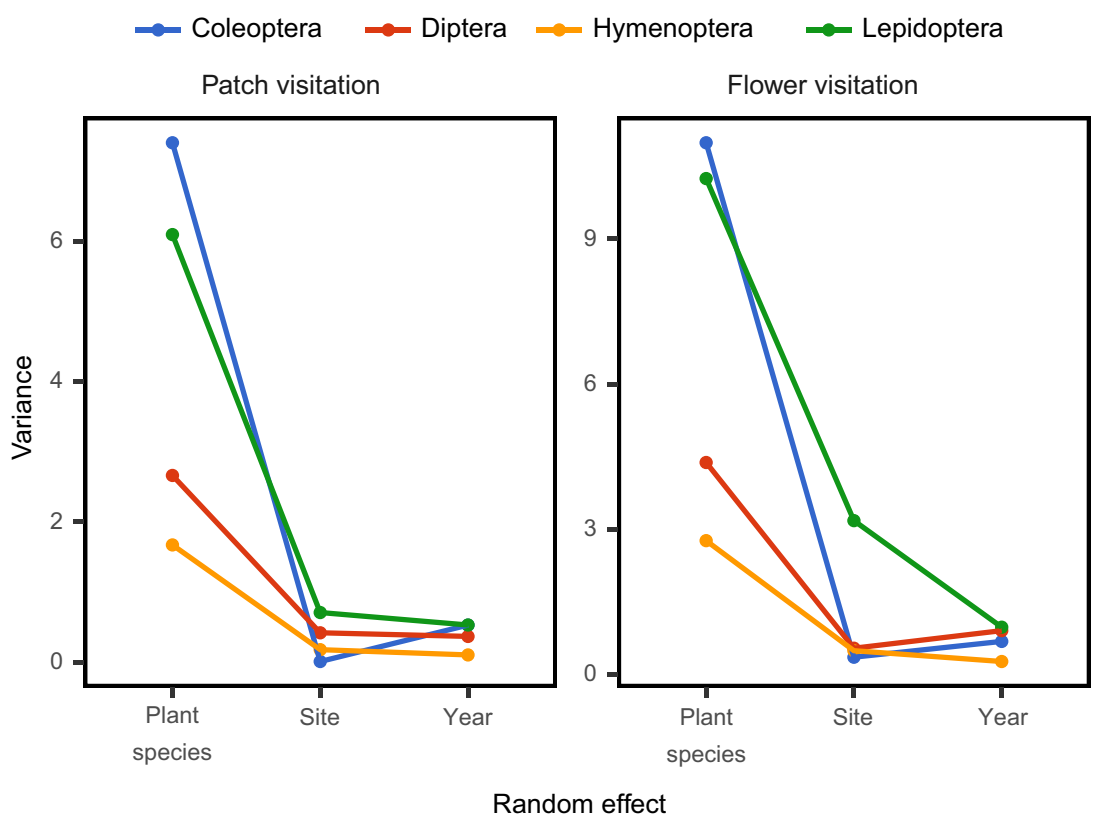

FIG. 2. Variance components of patch and flower visitation probability accounted for by plant species, sampling site, and sampling year in the data set studied, estimated separately for each major insect order. Patch visitation probability is the probability that some flower in a focal flowering patch is probed in 3 minutes and flower visitation probability is the probability that one individual flower is probed in 3 minutes. See Table 2 for the results for all pollinators combined. 


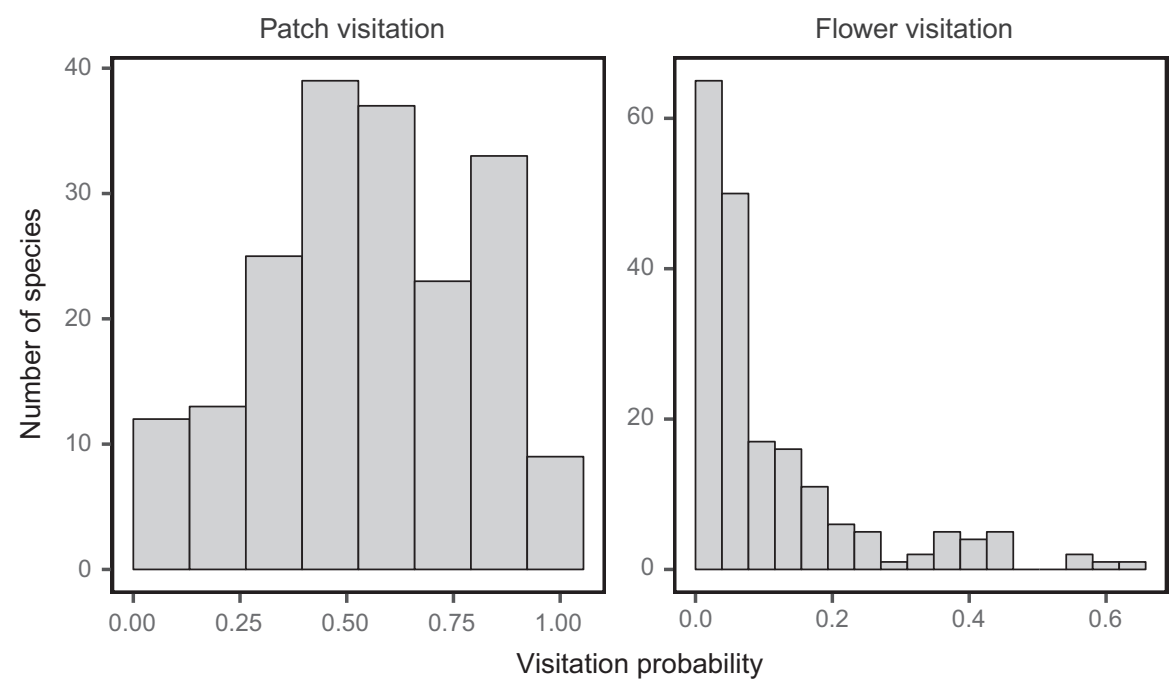

FIG. 3. Frequency distributions of plant species means for patch (probability that some flower in a focal flowering patch is probed in 3 minutes) and flower (probability that one individual flower is probed in 3 minutes) pollinator visitation probabilities, all pollinators combined $(N=191$ species $)$.

location in the phylogenetic tree was rejected. Tests for the presence of a phylogenetic signal for patch and flower visitation probability yielded statistically significant results, irrespective of whether tests referred to all pollinators combined or to individual insect orders considered separately (Table 3). The magnitude of phylogenetic structuring of patch and flower visitation probability, as assessed with Pagel's $\lambda$, varied among insect orders, being strongest for Coleoptera and weakest for Diptera and Lepidoptera (Table 3).

For all pollinators combined, global phylogenetic signal in the whole species sample mostly reflected a trend of increasing patch and flower visitation probabilities running from basal clades through more derived ones (Fig. 5). Nevertheless, the phylogenetic signal was not homogeneously distributed across the phylogenetic tree. There were statistically significant phylogenetic correlation hotspots characterized by low pollinator visitation probabilities within the Monocots, Ranunculales, and some Lamiales, while the Asterales as a whole exemplified a large, distinct hotspot of local phylogenetic correlations characterized by high patch and flower visitation probabilities (Fig. 5).

Separate consideration of patch and flower visitation probabilities by major insect groups revealed welldefined, order-specific patterns in the distribution of statistically significant autocorrelation hotspots in the phylogeny. For Coleoptera, distinct hotspots of high-visitation probabilities were associated with Malvales, Rosales, and some clades in Asterales, and one large hotspot of low visitation was associated with Lamiaceae (Fig. 5). The Diptera exhibited statistically significant hotspots of high visitation associated with Caryophyllales and some clades in Asterales, and significant hotspots of low visitation in some clades of Monocots and Lamiales. For the
Hymenoptera, significant hotspots of high visitation were restricted to Asterales, while hotspots characterized by low visitation occurred in several scattered clades within Monocots, Ranunculales, and Caryophyllales. Hotspots of high visitation by Lepidoptera were restricted to Asterales, while a large hotspot characterized by low visitation comprised all clades from Monocots to Rosales. The combination of the preceding trends led to several distinct patterns in pollinator composition associated with higher-level plant taxa and phylogenetic position. For example, species of Caryophyllales were simultaneously characterized by high-Diptera and lowHymenoptera visitation; species of Malvales by high visitation by Coleoptera and low visitation by Hymenoptera and Lepidoptera; species of Lamiales by low visitation of Coleoptera and Diptera; and most species of Asterales by a combination of high Hymenoptera and Lepidoptera visitation (Fig. 5).

\section{Pollinators and habitat type}

All pollinators combined.-Visitation by all pollinators combined varied widely among habitats. Generalized linear mixed models that included pollinator census date (days from 1 January) and number of flowers per patch as fixed-effect covariates, and plant species, sampling year, and sampling site as random effects, revealed statistically significant heterogeneity across habitat types in both patch $\left(\chi^{2}=51.92, \mathrm{df}=8, P=1.7 \times 10^{-8}\right)$ and flower visitation probability $\left(\chi^{2}=48.89, \quad \mathrm{df}=8\right.$, $\left.P=6.7 \times 10^{-8}\right)$. Flower patches and individual flowers on rock cliffs, forest interior and dolomitic outcrops had the lowest, and those in disturbances the highest, probabilities per time unit of being visited by pollinators (Fig. 6). 

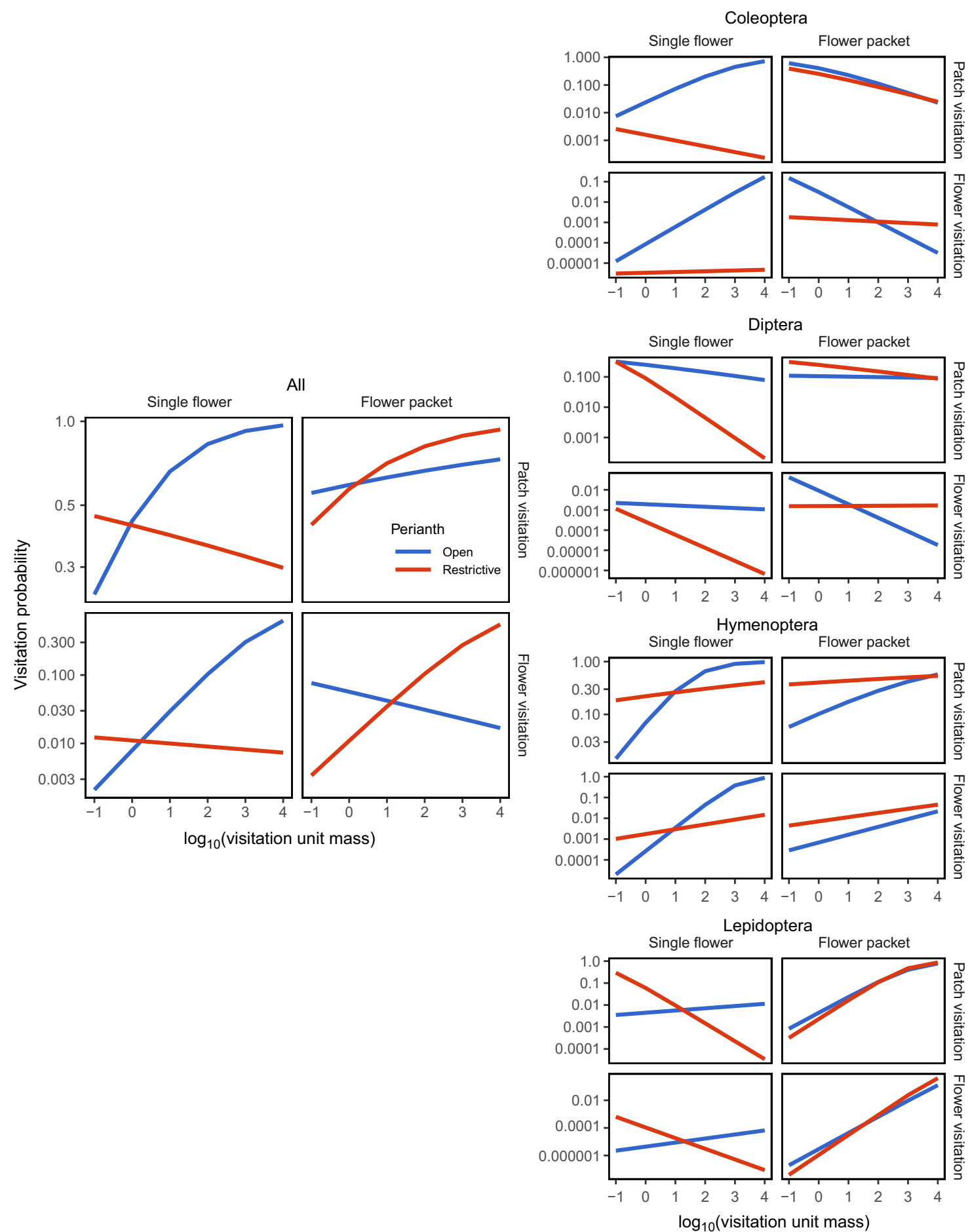

FIG. 4. Mean predicted marginal effects of visitation unit mass (measured as mg; $\log _{10}$-transformed) on patch and flower visitation probabilities (holding number of flowers per patch and day of year fixed), depicting interaction effects involving class of visitation unit (single flower vs. flower packet) and type of floral perianth (open vs. restrictive). Patch visitation probability is the probability that some flower in a focal flowering patch is probed in 3 minutes, and flower visitation probability is the probability that one individual flower is probed in 3 minutes. Graphs correspond to separate analyses conducted for all pollinators combined (left) and for each of the four major insect orders (right). Graphs were designed to emphasize differences between pollinator groups in the qualitative nature of interaction effects rather than quantitative differences in main effects, hence the different scales on vertical axes. See Appendix S5: Table S1 for statistical significance of main effects and interactions in models. 
TABle 3. Tests for the presence of phylogenetic signal in species means for patch visitation and flower visitation probabilities.

\begin{tabular}{lll}
\hline \hline & \multicolumn{2}{c}{ Pagel's $\lambda$} \\
\cline { 2 - 3 } Response variable and pollinator group & statistic & $P$ \\
\hline Patch visitation probability & & \\
All pollinators & 0.491 & 0.00001 \\
Coleoptera & 0.651 & 0.00001 \\
Diptera & 0.316 & 0.050 \\
Hymenoptera & 0.376 & 0.00002 \\
Lepidoptera & 0.208 & 0.00001 \\
Flower visitation probability & & \\
All pollinators & 0.422 & 0.00001 \\
Coleoptera & 0.879 & 0.00001 \\
Diptera & 0.125 & 0.12 \\
Hymenoptera & 0.293 & 0.00033 \\
Lepidoptera & 0.167 & 0.0013 \\
\hline
\end{tabular}

Notes: Mean values for patch visitation and flower visitation probabilities were computed for plant species, associated with the corresponding tips in the phylogenetic tree (Appendix S6: Fig. S1), and tested for phylogenetic signal. Statistical significance was obtained by randomization with $10^{5}$ repetitions. Patch visitation probability is the probability of at least one flower in a patch being probed during a 3-minute period. Flower visitation probability is the probability of visitation of an individual flower during a 3-minute period.

Major insect orders. - Patch and flower visitation probabilities by major insect orders considered separately varied significantly among habitat types $(P<0.0001$ in all cases), but the four groups did not vary in unison across habitats. A generalized linear mixed model similar to the one described in the preceding paragraph but whose main fixed effects were habitat type, insect order, and their interaction, revealed strong habitat $x$ insect order interactions on both patch visitation $\left(\chi^{2}=1,461.6\right.$, $\left.\mathrm{df}=24, P<2.2 \times 10^{-16}\right)$ and flower visitation probability $\left(\chi^{2}=9,848.8, \mathrm{df}=24, P<2.2 \times 10^{-16}\right)$. Mean predicted marginal effects of habitat type on patch and flower visitation probabilities (holding census date and number of flowers per patch fixed) for each insect order are shown in Fig. 7. In general, patch and flower visitation by Hymenoptera varied relatively little across habitat types, experiencing only minor reductions in dolomitic outcrops, forest interior, and rock cliffs. The rest of insect orders did exhibit broad variations among habitat types in patch and flower visitation. Coleoptera and Lepidoptera were the two groups exhibiting the most marked changes in patch and flower visitation probabilities across habitat types. Coleoptera had particularly low visitation probabilities in disturbances, dolomitic outcrops, forest interior, and rock cliffs, and high visitations in dwarf mountain scrub, grasslands and meadows, and tall sclerophyllous scrub. Lepidoptera visitation probabilities were highest in disturbances, forest clearings and edges, grasslands and meadows, and springs/streams, and lowest in forest interior and rock cliffs. Diptera had fairly constant, moderate-to-low-visitation probabilities in all habitat types except forest interior and rock cliffs, where they reached minimum values (Fig. 7).

There was a fairly predictable, habitat-dependent variation in proportional pollinator composition as a consequence of the decoupling across habitat types of patch and flower visitation probabilities by the different insect orders. Dwarf mountain scrub, grasslands and meadows, and forest clearings and edges, for example, were characterized by pollinator assemblages in which the four insect orders had roughly similar patch and flower visitation probabilities (Fig. 7). In dolomitic outcrops and rock cliffs the pollinator assemblages tended to be dominated by Hymenoptera and Diptera, while combinations of Hymenoptera, Diptera, and Lepidoptera were characteristic of disturbances and streams/springs.

Phylogenetic regressions on habitat type.-Results of phylogenetic regressions of mean patch and flower visitation probability per species on habitat type differed in some respects from those obtained from models ignoring phylogenetic correlations underlying pollinator visitation. For all pollinators combined, statistically significant effects of habitat type on patch and flower visitation probabilities persisted after controlling for phylogenetic correlations (Table 4). Patterns of variation among habitats were also closely similar to those depicted in Fig. 6, with rock cliffs, forest interior, and dolomitic outcrops exhibiting lower overall visitation probabilities than other habitat types (results not shown). Separate phylogenetic regressions for insect orders revealed statistically significant relationships between visitation probabilities and habitat type only for Hymenoptera. The visitation-habitat relationships were statistically nonsignificant for Coleoptera and Diptera, and significant for patch visitation only in the case of Lepidoptera (Table 4).

\section{Discussion}

Many different approaches have been used over the years to quantify pollinator visitation to flowers, although few of these allow for proper statistical comparisons as noted in the Introduction. The method used here, whereby pollinator visitation rate is measured in terms of the probability of flowering patches or individual flowers being visited in a given length of time, overcomes these limitations and can be universally applied to any plant species (Herrera 2019). It must be stressed that this method, albeit without explicit recognition of its probabilistic connotations and analytical advantages, was proposed long ago and applied in community studies by Arroyo et al. (1985) and Inouye and Pyke (1988). These authors also emphasized its value for comparative purposes. Despite these advantages, however, not many studies have adopted this method for quantifying pollinator visitation in plant community contexts (e.g., Motten 1986, Totland 1993, Lázaro et al. 2013). This fact, in combination with the much larger, phylogenetically 
A

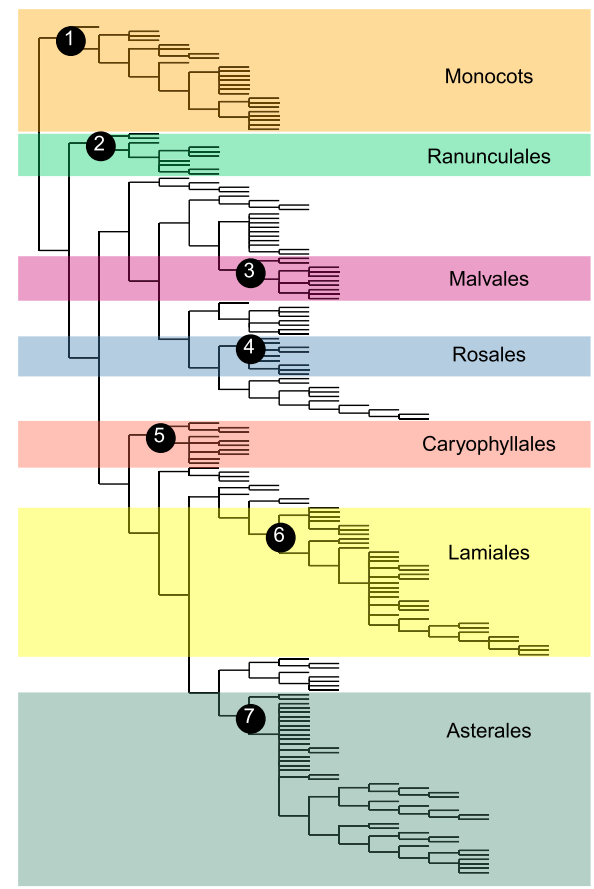

A

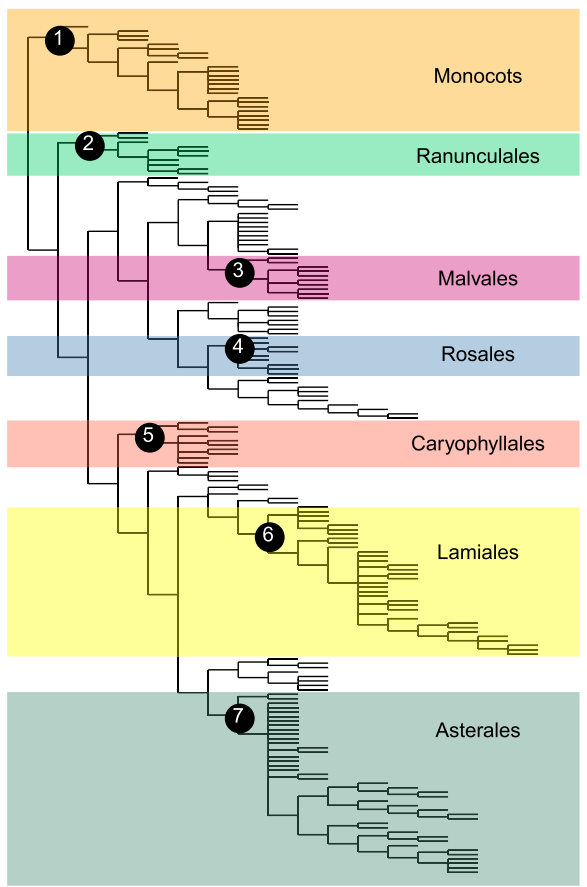

Patch visitation probability
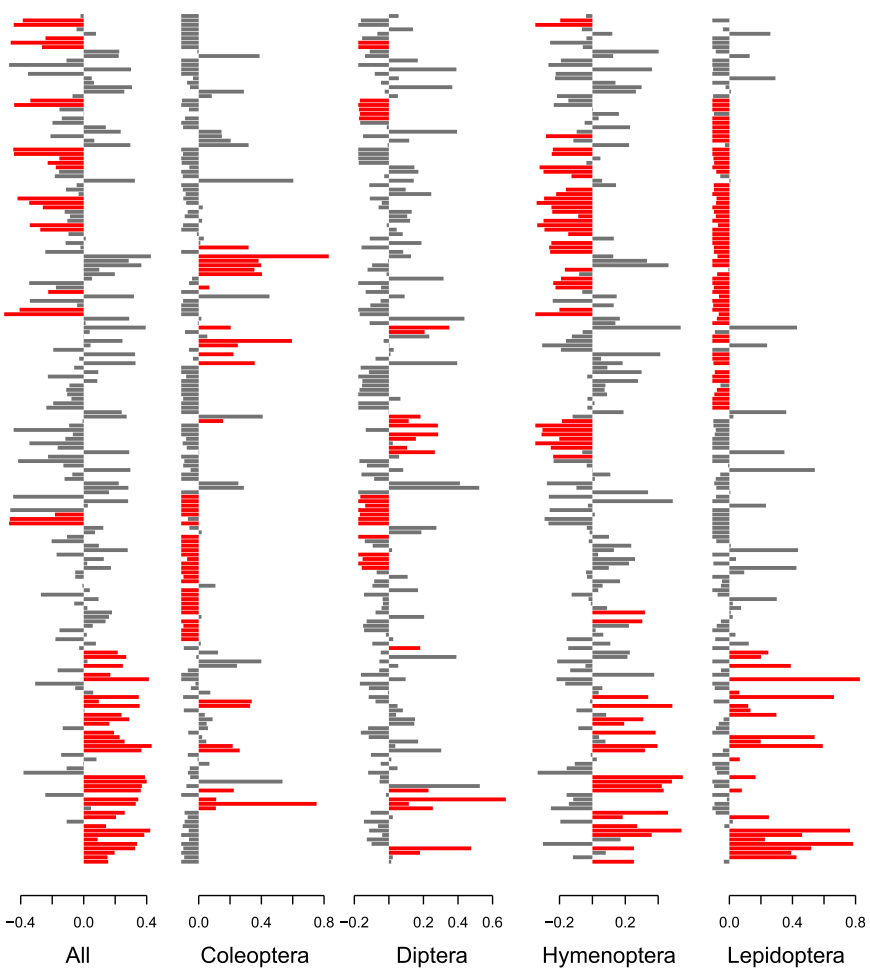

Flower visitation probability
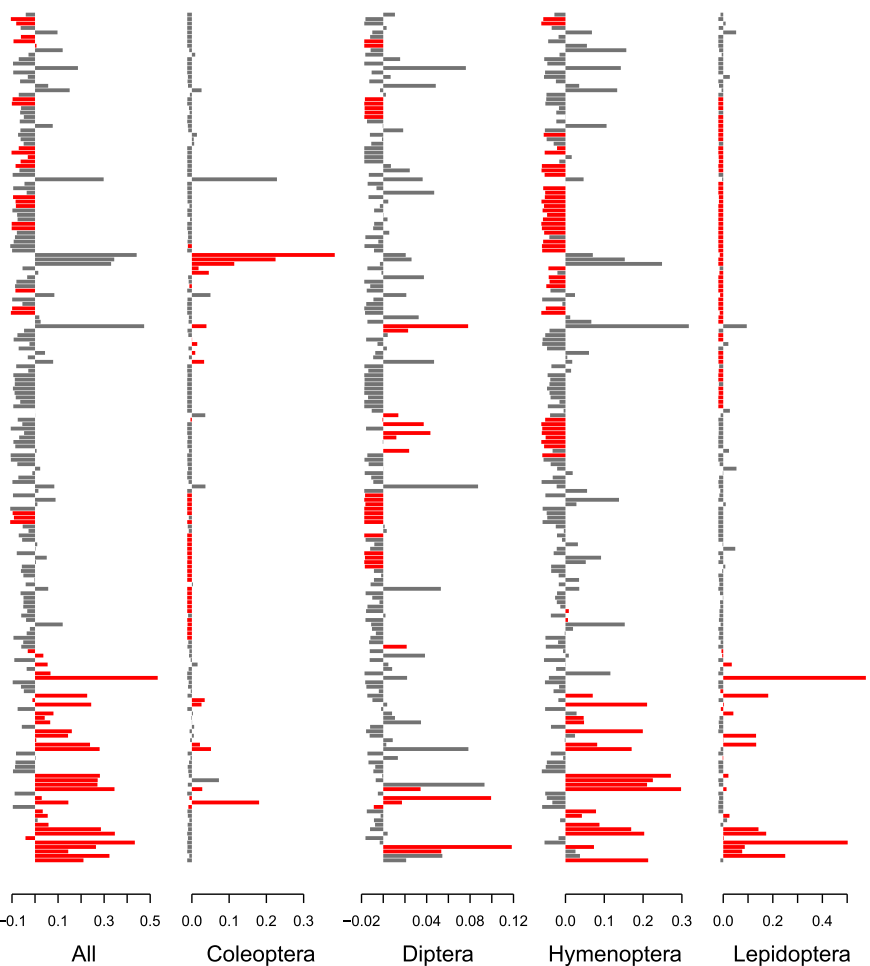

FIG. 5. Visualization of species means for (A) patch visitation probability and (B) flower visitation probability for the set of $N=191$ plant species studied in relation to the phylogenetic tree depicting their evolutionary relationships (see Appendix S6: 


\section{Fig. 5. (Continued)}

Fig. S1 for a tree with labeled tips). For each visitation measurement, separate panels are shown for all pollinators combined and for each major insect order (Coleoptera, Diptera, Hymenoptera, Lepidoptera). Each horizontal bar corresponds to one plant species, and its length and direction denote the mean visitation probability relative to the overall zero-centered sample mean, i.e., leftand right-facing bars correspond to values that are smaller and larger than the overall sample mean, respectively. Shown in red are species with statistically significant local Moran's $I_{\mathrm{i}}(P<0.05)$, denoting instances of local phylogenetic associations. Clusters of red-colored bars are indicative of "local hotspots" of phylogenetic autocorrelation for the particular group of pollinators and visitation measurement involved. Numbered clades correspond to phylogenetically and taxonomically defined groups of species mentioned in the text: 1, Monocots: all monocots in the sample; 2, Ranunculales: species of Berberidaceae, Ranunculaceae, and Papaveraceae; 3, Malvales: Thymelaeaceae and Cistaceae; 4, Rosales: Rosaceae; 5, Caryophyllales: Plumbaginaceae and Caryophyllaceae; 6, Lamiales: Scrophulariaceae, Lamiaceae, and Orobanchaceae; and 7, Asterales: Campanulaceae and Asteraceae.

more diverse sample considered here in comparison to most earlier community studies, will limit opportunities for discussing the results of this study in the context of earlier investigations.

\section{Pollinator visitation rate: a species-specific feature}

It has been shown many times that pollinator visitation rates vary among plant species and, within species, among locations and years (Husband and Barrett 1992, McCall and Primack 1992, Herrera et al. 2001, Price et al. 2005, Herrera 2019). I am not aware, however, of any previous attempt at explicitly partitioning the overall variance in pollinator visitation at the regional plant community level into components attributable to interspecific, spatial, and suprannual variation. By sampling many species in many years and sites, this study has been able to show that variation among species was by far the largest source of variance in total pollinator visitation (i.e., all pollinators combined) in the Sierra de Cazorla region. Variance components due to differences among years and sites, although significantly greater than zero, were much less important quantitatively than variance due to interspecific differences. Since most species were sampled at single sites and years, this result could be a spurious consequence of limited sampling in time and space. Nevertheless, the result was similar after computing variance components only for subsets of species that were sampled on more than one year or more than one site, which tends to rule out the possibility that the variance structure of the whole species sample was a spurious consequence of having sampled most species on single years and sites. Taken together, results of variance partitions point to the conclusion that, in the region and species sample studied, visitation rate by all pollinators was largely a species-specific attribute, and that
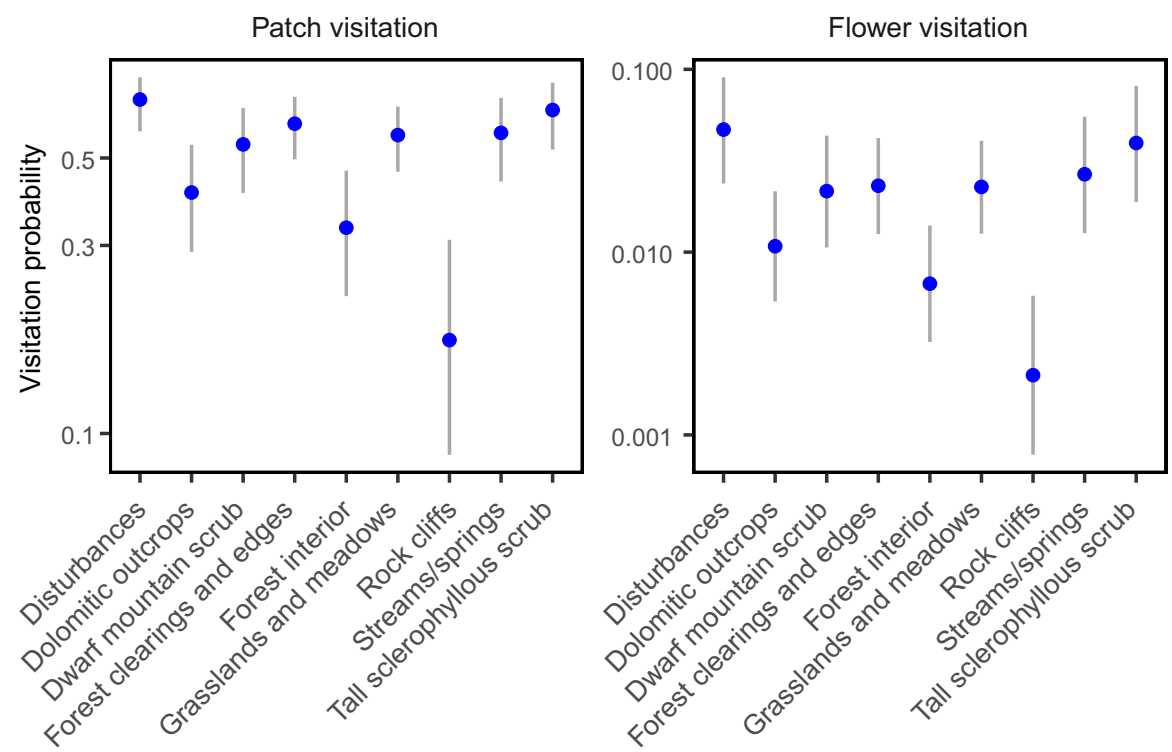

Habitat type

FIG. 6. Mean predicted marginal effects of habitat type on patch and flower visitation probabilities (dots), all pollinators combined (holding day of year and number of flowers per patch fixed). Vertical segments denote $95 \%$ confidence intervals. Note logarithmic scale on vertical axes. 


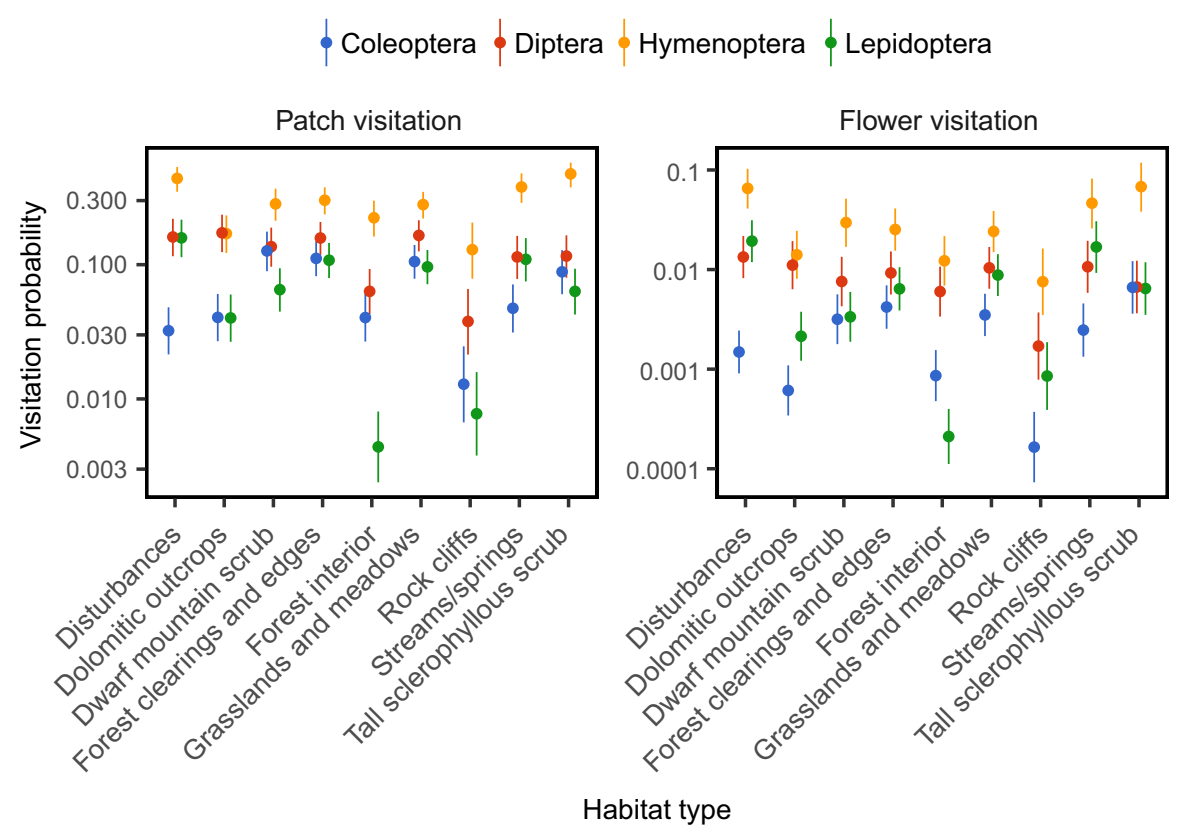

FIG. 7. Mean predicted marginal effects of habitat type on patch and flower visitation probabilities (dots), computed separately for each of the four major insect orders (holding day of year and number of flowers per patch fixed). Vertical segments denote $95 \%$ confidence intervals. Note logarithmic scale on vertical axes.

interspecific differences should be expected to be robust to the blurring effects of temporal and spatial intraspecific variations. Visual inspection of Figs. 3 and 4 in Herrera (2019) further adds to the view that, in the large species sample examined here, interspecific differences in visitation rates by all pollinators combined are likely to persist in the face of long-term suprannual changes experienced by individual plant species.

The large species sample examined in this study allowed estimation of both the range and the shape of the

TABLE 4. Results of phylogenetic regressions testing for the effect of habitat type on patch and flower visitation probabilities after statistically accounting for the significant phylogenetic correlations underlying pollinator visitation data.

\begin{tabular}{|c|c|c|c|c|}
\hline \multirow[b]{3}{*}{ Pollinator group } & \multicolumn{4}{|c|}{ Response variable } \\
\hline & \multicolumn{2}{|c|}{$\begin{array}{l}\text { Patch visitation } \\
\text { probability }\end{array}$} & \multicolumn{2}{|c|}{$\begin{array}{c}\text { Flower visitation } \\
\text { probability }\end{array}$} \\
\hline & $\chi^{2}$ & $P$ & $\chi^{2}$ & $P$ \\
\hline All pollinators & 71.22 & $2.8 \times 10^{-12}$ & 19.62 & 0.012 \\
\hline Coleoptera & 11.12 & 0.19 & 8.25 & 0.41 \\
\hline Diptera & 12.42 & 0.13 & 14.62 & 0.067 \\
\hline Hymenoptera & 48.53 & $7.8 \times 10^{-8}$ & 24.68 & 0.0017 \\
\hline Lepidoptera & 17.44 & 0.026 & 5.23 & 0.73 \\
\hline
\end{tabular}

Notes: For each response variable, analyses were performed for all pollinators combined and for each major insect order separately. Patch visitation probability is the probability of at least one flower in a patch being probed during a 3-minute period. Flower visitation probability is the probability of visitation of an individual flower during a 3-minute period. distributions of species means for patch and flower visitation probabilities. Interspecific differences in these two parameters were very broad, encompassing nearly three orders of magnitude and 200-fold ranges. This substantial variation, in addition to revealing extensive interspecific differences in pollinator service, enhanced the statistical power for identifying predictors of pollinator visitation, which could perhaps have remained undetected in a smaller species sample with narrower range of variation. The scarce comparative evidence available suggests that broad interspecific variation in pollinator service is probably the rule in most plant communities. Mean flower visitation probabilities for individual species obtained in this study are compared in Table 5 to published data from other community studies in different continents and vegetation types, after converting pollinator visitation figures to a common measurement unit. Community means and ranges of flower visitation probability were remarkably homogeneous across continents and vegetation types. For instance, the mean for Mediterranean montane species studied here was virtually identical to those from distant and ecologically dissimilar communities, such as boreal and alpine habitats in Norway or meadow-forest habitats in Massachusetts (Table 5). This suggests the intriguing possibility of ecological invariance in community-level descriptors of per-flower pollinator visitation, a hypothesis deserving further study.

\section{Pollinator visitation rate: intrinsic and extrinsic predictors}

All plant intrinsic and extrinsic predictors contributed to explain variation in patch and flower visitation 
TABLE 5. Pollinator visitation rates (all pollinators combined) from community studies conducted in different regions and vegetation types.

\begin{tabular}{|c|c|c|c|c|}
\hline \multirow[b]{2}{*}{ Vegetation type and region } & \multirow{2}{*}{$\begin{array}{l}\text { No. plant } \\
\text { species }\end{array}$} & \multicolumn{2}{|c|}{$\begin{array}{c}\text { Flower visitation probability } \\
\text { (visits/minute) }\end{array}$} & \multirow[b]{2}{*}{ Reference } \\
\hline & & Mean $\pm \mathrm{SE}$ & Range & \\
\hline Mediterranean montane, Spain & 191 & $0.037 \pm 0.003$ & $0.0011-0.2146$ & this study \\
\hline Alpine and boreal, Norway & $41 \dagger$ & $0.037 \pm 0.012$ & $0.0003-0.4050$ & $\begin{array}{l}\text { Totland (1993, 1994, 2001), Totland and Schulte- } \\
\text { Herbrüggen (2003), Hansen and Totland (2006), } \\
\text { Totland et al. (2006), Lundemo and Totland } \\
\text { (2007), Lázaro et al. (2013); A. Lázaro (personal } \\
\text { communication) }\end{array}$ \\
\hline Alpine, Australia & $36 \dagger$ & $0.016 \pm 0.003$ & $0.0002-0.0742$ & Inouye and Pyke (1988) \\
\hline $\begin{array}{l}\text { Alpine tundra, } \\
\text { New Hampshire, USA }\end{array}$ & 35 & $0.022 \pm 0.057$ & $\ddagger$ & McCall and Primack (1992) \\
\hline Deciduous forest, USA & 6 & $0.026 \pm 0.007$ & $0.0050-0.0453$ & Motten (1986) \\
\hline $\begin{array}{l}\text { Woodland-meadow (1982), } \\
\text { Massachusetts, USA }\end{array}$ & 124 & $0.035 \pm 0.101$ & + & McCall and Primack (1992) \\
\hline $\begin{array}{l}\text { Woodland-meadow (1983), } \\
\text { Massachusetts, USA }\end{array}$ & 108 & $0.034 \pm 0.069$ & + & McCall and Primack (1992) \\
\hline Tropical forest, Central America & 11 & $0.028 \pm 0.015$ & $0.0027-0.1610$ & Kay and Schemske (2003) \\
\hline Mountain fynbos, South Africa & 92 & $0.018 \pm 0.058$ & $\ddagger$ & McCall and Primack (1992) \\
\hline
\end{tabular}

Notes: Original figures were transformed to common units. In each region, multiple data for the same species were averaged.

$\dagger$ Only species with nonzero visitation records are included.

+ Visitation probabilities estimates for individual species were not available in the original publication.

probabilities, all pollinators combined. Among intrinsic predictors, the simple floral traits considered, namely perianth type, mass of visitation unit, and type of visitation unit, were all related to pollinator visitation. Simple functional relationships, however, could not be inferred due to interactions between predictors. For example, pollinator visitation increased steadily with increasing log mass of visitation unit, a surrogate for its size, but this relationship only held for species with single flowers with open perianths, or those with flower packets and restrictive perianths, but not for species possessing other trait combinations. Single flowers with open perianths tended to have higher visitation rates than those with restrictive perianth, but these relationships did not held for flower packets. Comparable relationships have been reported previously by the few studies that have examined interspecific relationship between floral traits and pollinator visitation at the plant community level (McCall and Primack 1992, Hegland and Totland 2005, Lázaro et al. 2013). In the present instance, positive relationships between pollinator visitation rates and log mass of visitation unit may be parsimoniously explained as a consequence of the direct relationship between perflower sugar secretion and flower log mass reported for southern Spanish plants (Herrera 1985), on the plausible assumption that consistently greater floral rewards should favor greater average visitation rates.

Another species-specific, intrinsic predictor having an effect on patch and flower visitation probabilities was the evolutionary history of each species as represented by its phylogenetic relationships. There was, on one side, a global phylogenetic trend in the sample roughly reflecting an increasing trend in visitation probabilities from basal through more derived clades. In addition, there were phylogenetic correlation hotspots characterized by either similarly low (Monocots, some Ranunculales, some Lamiales) or similarly high (most Asterales) pollinator visitation probabilities. To my knowledge, no previous study has examined variations in pollinator visitation rates in a broad phylogenetic framework, thus it is not possible to know whether phylogenetic patterns found here are representative for the angiosperms as a whole or apply only to my species sample. In addition, an even more phylogenetically encompassing species sample would be needed to ascertain whether phylogenetic patterns occurring in my sample are linked to the evolutionary trajectories of floral traits considered here or depend on other factors. Keeping these caveats in mind, two implications of the phylogenetic analyses shown here deserve consideration. First, the well-known differences between taxonomic groups and evolutionary lineages in incidence of pollen limitation (Larson and Barrett 2000, Knight et al. 2005, Alonso et al. 2010, Vamosi et al. 2013, Bennett et al. 2018) could reflect underlying, insufficiently recognized phylogenetic effects on pollinator visitation rates. It is worth noting in this regard that the ubiquitous pollen limitation occurring within the plant order Asparagales (Bennett et al. 2018: Fig. 3) is consistent with the low pollinator visitation rates found here for Monocots, most of which belong to Asparagales. And second, because of the overall phylogenetic signal and local hotspots of phylogenetic correlations in pollinator visitation, the taxonomic affiliation of species chosen for pollination investigations can sometimes predefine those conclusions of research that depend on pollinator visitation rates. This adds one 
more instance to the growing list of challenges to pollination studies due to unacknowledged geographic or taxonomic biases (Rodger et al. 2004, Archer et al. 2014, Ollerton et al. 2015, Herrera 2019).

Habitat type was a significant predictor of pollinator visitation rate. Among the nine habitat types recognized, dolomitic outcrops, forest interior, and, particularly, rock cliffs were characterized by comparatively low pollinator visitation at both the flowering patch and individual flower levels. These patterns could arise from habitat-specific ecological factors influencing pollinator visitation but, given the strong phylogenetic signal characterizing pollinator visitation rates in the sample, could also reflect possible phylogenetic niche conservatism if plant species that are closely related phylogenetically tended to occur in similar environments (Losos 2008, Münkemüller et al. 2015). The second possibility is not consistent with the results of phylogenetic regressions, which showed that the value of habitat type as a predictor of pollinator visitation persisted after statistically accounting for the phylogenetic relationships among species. Instead, habitat-specific ecological factors seem to account for the reduced pollinator service in dolomitic outcrops, forest interior and rock cliffs. In these three habitats, low attractiveness of flowering plants to pollinators due to scarcity of flowers in their immediate vicinity may have contributed to the low-visitation rates, since previous studies have often found that floral neighborhood characteristics are important determinants of pollinator visitation to individual plants or flowering patches (Laverty 1992, Molina-Montenegro et al. 2008, Montero-Castaño and Vilà 2015). In dolomitic outcrops, low pollinator visitation probably was also a consequence of strong interspecific competition for pollinator service arising from high diversity of sympatric entomophilous plants (Alonso et al. 2013) in combination with small size of local insect populations derived from aridity, low plant productivity and sparse vegetation. In the case of forest interior and rock cliffs, energetic constraints on foraging due to low density of flowering plants and thermal limitations on ectothermic pollinators set by the low solar irradiance available in these shady environments (Beattie 1971, Herrera 1995a, b, 1997, Zamora 1999) can also have reduced pollinator visitation.

\section{Pollinator composition: community-wide patterns}

Pollinator composition is an important component of pollinator service, since different pollinators vary in per-visit pollen transfer efficacy and quality of transferred pollen (Herrera 1987, Sahli and Conner 2007, King et al. 2013). Coleoptera, Diptera, Hymenoptera, and Lepidoptera, the main groups of insect pollinators in the species sample studied here, generally differ in quantity and/or quality of their pollination service. As a general trend, per-visit pollen removal or deposition tend to decline in the direction
Hymenoptera-Lepidoptera-Diptera-Coleoptera, although broad variations can occur within orders and exceptions to this ranking are frequent, depending on the particular plant and insect species concerned (Schemske and Horvitz 1984, Herrera 1987, Larsson 2005, Sahli and Conner 2007, Theiss et al. 2007, Koski et al. 2018). These four insect orders have also been traditionally related to distinct plant "pollination syndromes," or suites of floral characteristics that are associated to particular pollinator groups (Fægri and van der Pij1 1979, Fenster et al. 2004).

Pollinator composition, in terms of relative contributions of Coleoptera, Diptera, Hymenoptera, and Lepidoptera, varied extensively among species in the sample studied. The variation was essentially continuous, as revealed by the ordination analysis of the between-species dissimilarity matrix. Discontinuities in pollinator composition over the bivariate ordination plane did not exist, and discrete groups with species more similar to each other than to species in other groups were not recognizable. All possible combinations of relative pollinator importance of the four major insect orders were represented in the species sample, and the frequency distributions of relative importance were essentially unimodal in all cases. These results indicate, on one side, that the vast majority of plants in the montane habitats studied had generalized pollination systems, each species depending for pollination on two or more insect orders with disparate morphology and behavior. Similar pervasiveness of generalized pollination systems has been previously emphasized in other community studies (McCall and Primack 1992, Herrera 1996, Waser et al. 1996). And on the other side, the absence of distinct species clusters associated with particular pollinators falsifies expectations from "pollination syndromes" views postulating that plants partition the range of available pollinators by specializing on particular groups, a result that corroborates those of Ollerton et al. (2009; see also Ollerton et al. 2015). Consideration of the 10 species (5.2\% of total) exclusively or predominantly pollinated by single insect orders, and falling around the periphery of the species cluster obtained by the ordination analysis, further adds to the failure to support pollinator syndromes linked to distinct pollinator groups. Species that depended entirely or predominantly on the same insect order for pollination were conspicuously heterogeneous in their floral characteristics (Appendix S7: Fig. S1). It must be stressed, however, that the current state of pollinator visitation does not necessarily imply that certain pollinator groups did not drive the evolution of certain plant species toward certain morphologies, in which case there may have been true partitioning of pollinators in the plant species' evolutionary history.

\section{Pollinator composition: responses to predictors}

The continuous interspecific variation in pollinator composition occurring in the species sample studied can be parsimoniously explained in terms of the heterogeneous 
visitation responses of major insect groups to variation in floral traits, phylogeny, and habitat type. Insect orders differed in the specific flower trait combinations to which they were responsive and in the shape of the relationships. For example, visitation rates by Coleoptera increased with increasing visitation unit mass in species with single flowers, but declined in species with flower packets. Lepidoptera responded positively to increasing mass of visitation unit in species with flowers packets, but negatively in species with single flowers and restrictive perianths. Hymenoptera stood alone from the rest by responding positively to increasing mass of visitation unit in all instances, and their visitation rates were not impaired by restrictive perianths.

Pollinator composition of individual plant species depended strongly on phylogeny. Patch and flower visitation probabilities by all insect orders except Diptera exhibited strong phylogenetic signals, thus showing that evolutionarily related plant species were more similar to each other in visitation probabilities by the different insect orders than to species more distant phylogenetically. Phylogenetic signal, however, was not homogeneously distributed across the plant phylogeny, and the distribution of significant hotspots of local phylogenetic autocorrelation was specific to each insect order. These hotspots indistinctly arose from local similarity in either above- or under-average visitation rates, as illustrated by the high-visitation hotspots of Coleoptera and Lepidoptera associated with Malvales and Asterales, respectively; the low-visitation hotspots of Hymenoptera characterizing Caryophyllales; and the low-visitation hotspots of both Diptera and Coleoptera associated with Lamiales. There were some instances of complementarity between insect orders in their phylogenetic hotspots. For example, the Caryophyllales simultaneously exhibited a low-visitation hotspot for Hymenoptera and a high-visitation hotspot for Diptera. Even acknowledging that my species sample falls short at achieving a complete phylogenetic coverage of entomophilous angiosperms in the study region, these results provide compelling evidence that plant phylogeny alone is an important predictor of pollinator composition in terms of major insect groups. This relationship is not necessarily mediated by similarity of phylogenetically related taxa in macroscopic floral traits of the sort traditionally considered in studies focusing on pollination syndromes (Fægri and van der Pijl 1979, Fenster et al. 2004, Ollerton et al. 2009). This is illustrated in my sample by the high-Coleoptera hotspot associated with species of Malvales, which belong to families with disparate macroscopic floral traits (Cistaceae and Thymelaeaceae; compare Cistus and Daphne in Appendix S7: Fig. S1), or by species in the high-Diptera and low-Hymenoptera hotspot associated with Caryophyllales (compare Arenaria and Saponaria in Appendix S7: Fig. S1).

In addition to floral traits and phylogenetic relationships, habitat type was another key predictor of pollinator composition, as shown by the decoupled variation across habitat types in visitation rates by different insect groups. Visitation rates by Hymenoptera (mostly bees) varied little among habitat types, a result that contrasts with published reports of between-habitat heterogeneity in bee abundance in other Mediterranean regions (Torné-Noguera et al. 2014). Visitation by the remaining three insect orders varied in contrasting ways across habitats. Variation among habitats in pollinator composition was in part the consequence of phylogenetically related plant species with their distinctive pollinator assemblages tending to occur in similar environments. This phylogenetic conservatism hypothesis was supported for Coleoptera, Diptera, and Lepidoptera, but not for Hymenoptera. Significant effects of habitat type on visitation probabilities by the former three orders vanished after statistically accounting for the phylogenetic correlations underlying pollinator visitation data. In contrast, habitat effects on Hymenoptera abundance remained significant after accounting for phylogeny. It can be speculated that the comparative stability of Hymenoptera across habitats could be the outcome of homogeneity among habitats in the abundance of their common larval and adult food (nectar plus pollen), while the broad variation in abundance of the rest of pollinator groups may reflect heterogeneity between habitats in the supply of their highly heterogeneous larval and adult foods. No data are available to evaluate this ecological hypothesis. In conclusion, therefore, betweenhabitat differences in pollinator composition occurring in my study region were the composite outcome of habitat-specific, phylogenetically independent responses in the case of Hymenoptera, in combination with significant phylogenetic niche conservatism in the case of Coleoptera, Diptera, and Lepidoptera.

\section{Concluding Remarks}

In the long run, local and regional plant communities are molded by the concerted, continued, intricate action of evolutionary, historical, and ecological events, and for this reason, they accumulate considerable amounts of biological information about the past and current operation of these building forces (Herrera 1992, Ackerly 2004, Donoghue 2008). Pollination community studies involving large species samples thus have considerable potential for understanding the present-day ecology and past evolution of plant-pollinator interactions (Arroyo et al. 1982, 1985, Inouye and Pyke 1988, Herrera 1992, McCall and Primack 1992, Totland 1993, Lázaro et al. 2013). In contrast, small or modest species sets drawn from a much larger regional pool represent artificially assembled samples often selected for practical convenience rather than biological motivations, but they provide suitable arenas for detailed study of specific questions or testing particular hypotheses. These two "zooming-out" and "zooming-in" approaches, respectively, to the study of the ecology and evolution of plant pollination are bound to contribute complementary 
insights, since small or modest species samples will rarely represent truly scaled-down, phylogenetically and ecologically unbiased versions of whole plant communities. As noted in the Introduction, research relying on ambitious sampling efforts involving many plant species remains overly underrepresented in comparison to that focusing on single species or small samples. By examining a unusually large, phylogenetically and ecologically diverse sample of species, the present study has illustrated the hitherto underexploited potential of pollination community studies at the regional scale to (1) reveal the importance of interactions among species-specific floral traits as predictors of pollinator visitation and composition and also, possibly, pollen limitation; (2) shed new light on long-standing, controversial issues in pollination research such as, e.g., the reality of so-called "pollination syndromes" (Fenster et al. 2004, Ollerton et al. 2009); (3) identify potential avenues for future research, e.g., examining heterogeneity among habitats or geographical regions in pollinator service and pollen limitation in the context of the phylogenetic relationships among species; (4) formulate novel hypotheses and questions that could hardly have arisen from studies dealing with limited species samples, e.g., asking whether complementary phylogenetic hotspots exhibited by different pollinator groups reflect some relationships over an evolutionary time scale, or suggesting the possible ecological invariance of community-level descriptors of per-flower pollinator visitation; and (5) identify potential methodological cautions that should be taken into consideration by studies dealing with limited, phylogenetically biased species samples, e.g., the extent to which results of these studies can be tainted by phylogenetic signals in pollinator abundance and composition not being accounted for. More generally, results of this study have shown that, given sufficient ecological and phylogenetic diversity in a species sample, components of pollinator service can be predicted by considering a few simple flower features, habitat type and evolutionary history.

\section{ACKNOWLEDGMENTS}

This study would not have been accomplished without the help of insect taxonomists that over the years dealt with my queries, shared their knowledge, and identified specimens. Special thanks are due to Oscar Aguado (Apoidea, Symphyta), Jorge Almeida (Diptera), Miguel A. Alonso Zarazaga (Coleoptera), Piluca Álvarez (Diptera), Stig Andersen (Tachinidae), Rui Andrade (Diptera), Enrique Asensio (Apoidea), Marcos Báez (Bombyliidae), Leopoldo Castro (Bombus, Vespoidea), Antonio Cobos (Buprestidae), José García Carrillo (Anthicidae), Severiano F. Gayubo (Crabronidae, Sphecidae), María Ángeles Marcos (Syrphidae), Andreas Müller (Anthidiini), Rafael Obregón (Coleoptera, Lepidoptera), Concepción Ornosa (Apoidea), Francisco J. Ortiz-Sánchez (Apoidea), José Carlos Otero (Nitidulidae), Florent Prunier (Orthoptera), Antonio Ricarte (Syrphidae), Knut Rognes (Calliphoridae), Luis Rozas (Coleoptera, Neuroptera), Arabia Sánchez Terrón (Bombyliidae), Klaus Schönitzer (Andrena), Alberto Tinaut (Formicidae), Hans-Peter Tschorsnig (Tachinidae), and José Luis Yela (Lepidoptera).
Alfredo Benavente and Gabriel Blanca assisted with some challenging plant identifications. Pollinator censuses on Helleborus foetidus were done in collaboration with Joaquín Cerdá, Begoña García (1998, 1999), Miyuki Macías, Mónica Medrano, and Curro Molina (2012, 2013). María Clara Castellanos did part of the censuses on Aquilegia vulgaris. Amparo Lázaro provided unpublished pollinator visitation data for Table 5. David Inouye and one anonymous reviewer contributed helpful comments and suggestions on the manuscript. Consejería de Medio Ambiente, Junta de Andalucía, granted permission to work in the Sierra de Cazorla and provided invaluable facilities there. Mónica Medrano provided insightful ideas, encouragement and inspiring discussions over so many years. The research reported in this paper received no specific grant from any funding agency.

\section{Literature Cited}

Ackerly, D. D. 2004. Adaptation, niche conservatism, and convergence: comparative studies of leaf evolution in the California chaparral. American Naturalist 163:654-671.

Aizen, M. A., and L. D. Harder. 2007. Expanding the limits of the pollen-limitation concept: effects of pollen quantity and quality. Ecology 88:271-281.

Alonso, C., J. C. Vamosi, T. M. Knight, J. A. Steets, and T. L. Ashman. 2010. Is reproduction of endemic plant species particularly pollen limited in biodiversity hotspots? Oikos 119:1192-1200.

Alonso, C., C. M. Herrera, and T. L. Ashman. 2012. A piece of the puzzle: a method for comparing pollination quality and quantity across multiple species and reproductive events. New Phytologist 193:532-542.

Alonso, C., C. M. Navarro-Fernández, G. Arceo-Gómez, G. A. Meindl, V. Parra-Tabla, and T. L. Ashman. 2013. Amongspecies differences in pollen quality and quantity limitation: implications for endemics in biodiverse hotspots. Annals of Botany 112:1461-1469.

Anselin, L. 1995. Local indicators of spatial association-LISA. Geographical Analysis 27:93-115.

Archer, C. R., C. W. W. Pirk, L. G. Carvalheiro, and S. W. Nicolson. 2014. Economic and ecological implications of geographic bias in pollinator ecology in the light of pollinator declines. Oikos 123:401-407.

Arroyo, M. T. K., R. Primack, and J. Armesto. 1982. Community studies in pollination ecology in the high temperate Andes of central Chile. I. Pollination mechanisms and altitudinal variation. American Journal of Botany 69:82-97.

Arroyo, M. T. K., J. J. Armesto, and R. B. Primack. 1985. Community studies in pollination ecology in the high temperate Andes of central Chile. II. Effect of temperature on visitation rates and pollination possibilities. Plant Systematics and Evolution 149:187-203.

Ashman, T. L., et al. 2004. Pollen limitation of plant reproduction: ecological and evolutionary causes and consequences. Ecology 85:2408-2421.

Bates, D., M. Maechler, B. Bolker, and S. Walker. 2015. Fitting linear mixed-effects models using lme4. Journal of Statistical Software 67:1-48.

Beattie, A. J. 1971. Itinerant pollinators in a forest. Madroño 21:120-124.

Bennett, J. M., et al. 2018. GloPL, a global data base on pollen limitation of plant reproduction. Scientific Data 5:180249.

Blanca, G., B. Cabezudo, M. Cueto, C. Morales Torres, and C. Salazar, editors. 2011. Flora vascular de Andalucía oriental. Second edition. Consortium of Universities of Almería, Granada, Jaén and Málaga, Granada, Spain. 
Blomberg, S. P., and T. Garland. 2002. Tempo and mode in evolution: phylogenetic inertia, adaptation and comparative methods. Journal of Evolutionary Biology 15:899-910.

Bolker, B. M. 2015. Linear and generalized linear mixed models. Pages 309-333 in G. A. Fox, S. Negrete-Yankelevich, and V. J. Sosa, editors. Ecological statistics: contemporary theory and application. Oxford University Press, Oxford, UK.

Burd, M. 1994. Bateman's principle and plant reproduction: the role of pollen limitation in fruit and seed set. Botanical Review 60:83-139.

Burd, M. 2016. Pollen limitation is common-Should it be? American Naturalist 187:388-396.

Chamberlain, S. 2018. brranching: Fetch 'phylogenies' from many sources. R package version 0.4 .0 . https://CRAN.R-pro ject.org/package $=$ brranching

Donoghue, M. J. 2008. A phylogenetic perspective on the distribution of plant diversity. Proceedings of the National Academy of Sciences USA 105:11549-11555.

Engel, E. C., and R. E. Irwin. 2003. Linking pollinator visitation rate and pollen receipt. American Journal of Botany 90:1612-1618.

Fægri, K., and L. van der Pijl. 1979. The principles of pollination ecology. Third edition. Pergamon Press, Oxford, UK.

Fenster, C. B., W. S. Armbruster, P. Wilson, M. R. Dudash, and J. D. Thomson. 2004. Pollination syndromes and floral specialization. Annual Review of Ecology, Evolution and Systematics 35:375-403.

Fox, J., and S. Weisberg. 2011. An R companion to applied regression. Second edition. Sage Publishing, Thousand Oaks, California, USA

Gómez Mercado, F. 2011. Vegetación y flora de la Sierra de Cazorla. Guineana 17:1-481.

Gómez, J. M., J. Bosch, F. Perfectti, J. Fernández, and M. Abdelaziz. 2007. Pollinator diversity affects plant reproduction and recruitment: the tradeoffs of generalization. Oecologia 153:597-605.

Gómez, J. M., M. Abdelaziz, J. Lorite, A. J. Muñoz-Pajares, and F. Perfectti. 2010. Changes in pollinator fauna cause spatial variation in pollen limitation. Journal of Ecology 98:1243-1252.

Grafen, A. 1989. The phylogenetic regression. Philosophical Transactions of the Royal Society B 326:119-157.

Gross, R. S., and P. A. Werner. 1983. Relationships among flowering phenology, insect visitors, and seed-set of individuals: experimental studies on four co-occurring species of goldenrod (Solidago: Compositae). Ecological Monographs 53:95-117.

Hansen, V. I., and O. Totland. 2006. Pollinator visitation, pollen limitation, and selection on flower size through female function in contrasting habitats within a population of Campanula persicifolia. Canadian Journal of Botany 84:412-420.

Harder, L. D., and M. A. Aizen. 2010. Floral adaptation and diversification under pollen limitation. Philosophical Transactions of the Royal Society B 365:529-543.

Harder, L. D., M. A. Aizen, and S. A. Richards. 2016. The population ecology of male gametophytes: the link between pollination and seed production. Ecology Letters 19:497-509.

Hegland, S. J., and Ø. Totland. 2005. Relationships between species' floral traits and pollinator visitation in a temperate grassland. Oecologia 145:586-594.

Hegland, S. J., and Ø. Totland. 2008. Is the magnitude of pollen limitation in a plant community affected by pollinator visitation and plant species specialisation levels? Oikos 117:883-891.

Herrera, J. 1985. Nectar secretion patterns in southern Spanish Mediterranean scrublands. Israel Journal of Botany 34:47-58.

Herrera, C. M. 1987. Components of pollinator 'quality': comparative analysis of a diverse insect assemblage. Oikos 50:7990.
Herrera, C. M. 1990. Daily patterns of pollinator activity, differential pollinating effectiveness, and floral resource availability, in a summer-flowering Mediterranean shrub. Oikos 58:277-288.

Herrera, C. M. 1992. Historical effects and sorting processes as explanations of contemporary ecological patterns: character syndromes in Mediterranean woody plants. American Naturalist 140:421-446.

Herrera, C. M. 1995a. Floral biology, microclimate, and pollination by ectothermic bees in an early-blooming herb. Ecology $76: 218-228$.

Herrera, C. M. 1995b. Microclimate and individual variation in pollinators: flowering plants are more than their flowers. Ecology 76:1516-1524.

Herrera, C. M. 1996. Floral traits and plant adaptation to insect pollinators: a devil's advocate approach. Pages 65-87 in D. G. Lloyd and S. C. H. Barrett, editors. Floral biology. Chapman and Hall, New York, New York, USA.

Herrera, C. M. 1997. Thermal biology and foraging responses of insect pollinators to the forest floor irradiance mosaic. Oikos 78:601-611.

Herrera, C. M. 2019. Complex long-term dynamics of pollinator abundance in undisturbed Mediterranean montane habitats over two decades. Ecological Monographs 89:e01338.

Herrera, C. M., A. M. Sánchez-Lafuente, M. Medrano, J. Guitián, X. Cerdá, and P. Rey. 2001. Geographical variation in autonomous self-pollination levels unrelated to pollinator service in Helleborus foetidus (Ranunculaceae). American Journal of Botany 88:1025-1032.

Husband, B. C., and S. C. H. Barrett. 1992. Pollinator visitation in populations of tristylous Eichhornia paniculata in northeastern Brazil. Oecologia 89:365-371.

Inouye, D. W., and G. H. Pyke. 1988. Pollination biology in the Snowy Mountains of Australia: comparisons with montane Colorado, USA. Australian Journal of Ecology 13:191-210.

Johnson, S. D., and W. J. Bond. 1997. Evidence for widespread pollen limitation of fruiting success in Cape wildflowers. Oecologia 109:530-534.

Kay, K. M., and D. W. Schemske. 2003. Pollinator assemblages and visitation rates for 11 species of neotropical Costus (Costaceae). Biotropica 35:198-207.

Kearns, C. A., and D. W. Inouye. 1993. Techniques for pollination biologists. University Press of Colorado, Niwot, Colorado, USA.

Keck, F., F. Rimet, A. Bouchez, and A. Franc. 2016. phylosignal: an $\mathrm{R}$ package to measure, test, and explore the phylogenetic signal. Ecology and Evolution 6:2774-2780.

King, C., G. Ballantyne, and P. G. Willmer. 2013. Why flower visitation is a poor proxy for pollination: measuring singlevisit pollen deposition, with implications for pollination networks and conservation. Methods in Ecology and Evolution $4: 811-818$.

Knight, T. M., J. A. Steets, J. C. Vamosi, S. J. Mazer, M. Burd, D. R. Campbell, M. R. Dudash, M. O. Johnston, R. J. Mitchell, and T. L. Ashman. 2005. Pollen limitation of plant reproduction: pattern and process. Annual Review of Ecology Evolution and Systematics 36:467-497.

Knuth, P. 1908. Handbook of flower pollination. Volume 2. Translated by J. R. Ainsworth Davis, Clarendon, Oxford, UK.

Korner-Nievergelt, F., T. Roth, S. von Felten, J. Guelat, B. Almasi, and P. Korner-Nievergelt. 2015. Bayesian data analysis in ecology using linear models with R, BUGS and Stan. Elsevier, Amsterdam, The Netherlands.

Koski, M. H., J. L. Ison, A. Padilla, A. Q. Pham, and L. F. Galloway. 2018. Linking pollinator efficiency to patterns of pollen limitation: small bees exploit the plant-pollinator 
mutualism. Proceedings of the Royal Society B 285:20180635.

Larson, B. M. H., and S. C. H. Barrett. 2000. A comparative analysis of pollen limitation in flowering plants. Biological Journal of the Linnean Society 69:503-520.

Larsson, M. 2005. Higher pollinator effectiveness by specialist than generalist flower-visitors of unspecialized Knautia arvensis (Dipsacaceae). Oecologia 146:394-403.

Laverty, T. M. 1992. Plant interactions for pollinator visits: a test of the magnet species effect. Oecologia 89:502-508.

Lázaro, A., A. Jakobsson, and O. Totland. 2013. How do pollinator visitation rate and seed set relate to species' floral traits and community context? Oecologia 173:881-893.

Losos, J. B. 2008. Phylogenetic niche conservatism, phylogenetic signal and the relationship between phylogenetic relatedness and ecological similarity among species. Ecology Letters 11:995-1003.

Lüdecke, D. 2018. ggeffects: Create tidy data frames of marginal effects for 'ggplot' from model outputs. R package version 0.3.1. https://CRAN.R-project.org/package $=$ ggeffects

Lundemo, S., and O. Totland. 2007. Within-population spatial variation in pollinator visitation rates, pollen limitation on seed set, and flower longevity in an alpine species. Acta Oecologica 32:262-268.

McCall, C., and R. B. Primack. 1992. Influence of flower characteristics, weather, time of day, and season on insect visitation rates in three plant communities. American Journal of Botany 79:434-442.

McLean, R. A., W. L. Sanders, and W. W. Stroup. 1991. A unified approach to mixed linear models. American Statistician 45:54-64.

Médail, F., and K. Diadema. 2009. Glacial refugia influence plant diversity patterns in the Mediterranean Basin. Journal of Biogeography 36:1333-1345.

Molina-Montenegro, M. A., E. I. Badano, and L. A. Cavieres. 2008. Positive interactions among plant species for pollinator service: assessing the 'magnet species' concept with invasive species. Oikos 117:1833-1839.

Molina-Venegas, R., and M. Á. Rodríguez. 2017. Revisiting phylogenetic signal; strong or negligible impacts of polytomies and branch length information? BMC Evolutionary Biology 17:53.

Molina-Venegas, R., A. Aparicio, J. A. Slingsby, S. Lavergne, and J. Arroyo. 2015. Investigating the evolutionary assembly of a Mediterranean biodiversity hotspot: deep phylogenetic signal in the distribution of eudicots across elevational belts. Journal of Biogeography 42:507-518.

Montero-Castaño, A., and M. Vilà. 2015. Direct and indirect influence of non-native neighbours on pollination and fruit production of a native plant. PLoS ONE 10:e0128595.

Motten, A. F. 1986. Pollination ecology of the spring wildflower community of a temperate deciduous forest. Ecological Monographs 56:21-42.

Müller, H. 1883. The fertilisation of flowers. Translated by D. W. Thompson. MacMillan, London, UK.

Münkemüller, T., S. Lavergne, B. Bzeznik, S. Dray, T. Jombart, K. Schiffers, and W. Thuiller. 2012. How to measure and test phylogenetic signal. Methods in Ecology and Evolution 3:743-756.

Münkemüller, T., F. C. Boucher, W. Thuiller, and S. Lavergne. 2015. Phylogenetic niche conservatism - common pitfalls and ways forward. Functional Ecology 29:627-639.

Oksanen, J., et al. 2019. vegan: Community ecology package. R package version 2.5-4. https://CRAN.R-project.org/package= vegan

Olesen, J. M., and P. Jordano. 2002. Geographic patterns in plant-pollinator mutualistic networks. Ecology 83:2416-2424.
Ollerton, J. 2017. Pollinator diversity: distribution, ecological function, and conservation. Annual Review of Ecology, Evolution, and Systematics 48:353-376.

Ollerton, J., R. Alarcón, N. M. Waser, M. V. Price, S. Watts, L. Cranmer, A. Hingston, C. I. Peter, and J. Rotenberry. 2009. A global test of the pollination syndrome hypothesis. Annals of Botany 103:1471-1480.

Ollerton, J., R. Winfree, and S. Tarrant. 2011. How many flowering plants are pollinated by animals? Oikos 120:321326.

Ollerton, J., A. Rodrigo Rech, N. M. Waser, and M. V. Price. 2015. Using the literature to test pollination syndromessome methodological cautions. Journal of Pollination Ecology 16:119-125.

Paradis, E. 2012. Analysis of phylogenetics and evolution with R. Second edition. Springer, New York, New York, USA.

Paradis, E., and K. Schliep. 2018. ape 5.0: An environment for modern phylogenetics and evolutionary analyses in R. Bioinformatics 35:526-528.

Pinheiro, J., D. Bates, S. DebRoy, D. Sarkar, and R Core Team. 2018. nlme: Linear and nonlinear mixed effects models. $\mathrm{R}$ package version 3.1-137. https://CRAN.Rproject.org/packa ge $=$ nlme

Plowright, R. C. 1981. Nectar production in the boreal forest lily Clintonia borealis. Canadian Journal of Botany 59:156-160.

Price, M. V., N. M. Waser, R. E. Irwin, D. R. Campbell, and A. K. Brody. 2005. Temporal and spatial variation in pollination of a montane herb: a seven-year study. Ecology 86:21062116.

Primack, R. B., and D. W. Inouye. 1993. Factors affecting pollinator visitation rates: a biogeographic comparison. Current Science 65:257-262.

R Core team. 2018. R: a language and environment for statistical computing. R Foundation for Statistical Computing, Vienna, Austria. https://www.R-project.org/

Robertson, C. 1928. Flowers and insects. Lists of visitors of four hundred and fifty-three flowers. Science Press, Lancaster, Pennsylvania, USA.

Rodger, J. G., K. Balkwill, and B. Gemmill. 2004. African pollination studies: where are the gaps? International Journal of Tropical Insect Science 24:5-28.

Rush, S., J. K. Conner, and P. Jennetten. 1995. The effects of natural variation in pollinator visitation on rates of pollen removal in wild radish, Raphanus raphanistrum (Brassicaceae). American Journal of Botany 82:1522-1526.

Sahli, H. F., and J. K. Conner. 2007. Visitation, effectiveness, and efficiency of 15 genera of visitors to wild radish, Raphanus raphanistrum (Brassicaceae). American Journal of Botany 94:203-209.

Schemske, D. W., and C. C. Horvitz. 1984. Variation among floral visitors in pollination ability: a precondition for mutualism specialization. Science 225:519-521.

Silander, J. A., and R. B. Primack. 1978. Pollination intensity and seed set in the evening primrose (Oenothera fruticosa). American Midland Naturalist 100:213-216.

Stanton, M. L., and R. E. Preston. 1988. Ecological consequences and phenotypic correlates of petal size variation in wild radish, Raphanus sativus (Brassicaceae). American Journal of Botany 75:528-539.

Symonds, M. R. E., and S. P. Blomberg. 2014. A primer on phylogenetic generalised least squares. Pages 105-130 in L. Z. Garamszegi, editor. Modern phylogenetic comparative methods and their application in evolutionary biology. Springer, Berlin, Germany.

Theiss, K., S. Kephart, and C. T. Ivey. 2007. Pollinator effectiveness on co-occurring milkweeds (Asclepias; Apocynaceae, 
Asclepiadoideae). Annals of the Missouri Botanical Garden 94:505-516.

Torné-Noguera, A., A. Rodrigo, X. Arnan, S. Osorio, H. Barril-Graells, L. C. da Rocha, and J. Bosch. 2014. Determinants of spatial distribution in a bee community: nesting resources, flower resources, and body size. PLoS ONE 9: e97255.

Totland, Ø. 1993. Pollination in alpine Norway: flowering phenology, insect visitors, and visitation rates in two plant communities. Canadian Journal of Botany 71:10721079.

Totland, Ø. 1994. Intraseasonal variation in pollination intensity and seed set in an alpine population of Ranunculus acris in southwestern Norway. Ecography 17:159-165.

Totland, Ø. 2001. Environment-dependent pollen limitation and selection on floral traits in an alpine species. Ecology 82:2233-2244.

Totland, Ø., and B. Schulte-Herbrüggen. 2003. Breeding system, insect flower visitation, and floral traits of two alpine
Cerastium species in Norway. Arctic, Antarctic, and Alpine Research 35:242-247.

Totland, Ø., A. Nielsen, A. L. Bjerknes, and M. Ohlson. 2006. Effects of an exotic plant and habitat disturbance on pollinator visitation and reproduction in a boreal forest herb. American Journal of Botany 93:868-873.

Vamosi, J. C., T. M. Knight, J. A. Steets, S. J. Mazer, M. Burd, and T. L. Ashman. 2006. Pollination decays in biodiversity hotspots. Proceedings of the National Academy of Sciences USA 103:956-961.

Vamosi, J. C., J. A. Steets, and T.-L. Ashman. 2013. Drivers of pollen limitation: macroecological interactions between breeding system, rarity, and diversity. Plant Ecology and Diversity 6:171-180.

Waser, N. M., L. Chittka, M. V. Price, N. M. Williams, and J. Ollerton. 1996. Generalization in pollination systems, and why it matters. Ecology 77:1043-1060.

Zamora, R. 1999. Conditional outcomes of interactions: the pollinator-prey conflict of an insectivorous plant. Ecology 80:786-795.

\section{SUPPORTING INFORMATION}

Additional supporting information may be found online at: http://onlinelibrary.wiley.com/doi/10.1002/ecm.1402/full

Data Availability

Data and R scripts are available in the Dryad Digital Repository: https://doi.org/10.5061/dryad.wh70rxwj3 